\title{
Finite-element investigation of cold-formed steel portal frames in fire
}

1 Ross P.D. Johnston MEng, PhD, AlFireE

Structural and Fire Safety Engineer, Hanna+Hutchinson Consulting Engineers Ltd, Lisburn, Northern Ireland, UK; School of Planning, Architecture and Civil Engineering, Queen's University Belfast, Belfast, Northern Ireland, UK

2. James B.P. Lim BEng, PhD, MICE

Senior Lecturer, University of Auckland, Auckland, New Zealand; Honorary Senior Lecturer, School of Planning, Architecture and Civil Engineering, Queen's University Belfast, Belfast, Northern Ireland, UK

3 Hieng Ho Lau BEng, PhD, PEng, MIEM Associate Professor, Curtin University, Sarawak Campus, Miri, Malaysia
4 Yixiang $\mathrm{Xu}$ BEng, $\mathrm{PhD}$

Lecturer, Department of Civil and Environmental Engineering, University of Strathclyde, Glasgow, UK

5 Mohammed Sonebi MEng, MSC, PhD, PGCHET, MCS, MACl, MRILEM, MASTM, Mfib

Senior Lecturer, School of Planning, Architecture and Civil

Engineering, Queen's University Belfast, Belfast, Northern Ireland, UK

6 Cecil G. Armstrong $\mathrm{PhD}$

Professor, School of Mechanical and Aerospace Engineering, Queen's University Belfast, Belfast, Northern Ireland, UK

7 Chee Chiang Mei BEng Managing Director, EcoSteel Sdn Bhd, Kuching, Sarawak, Malaysia
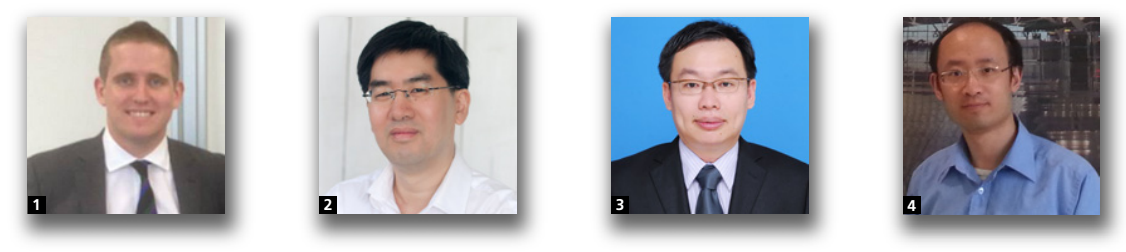
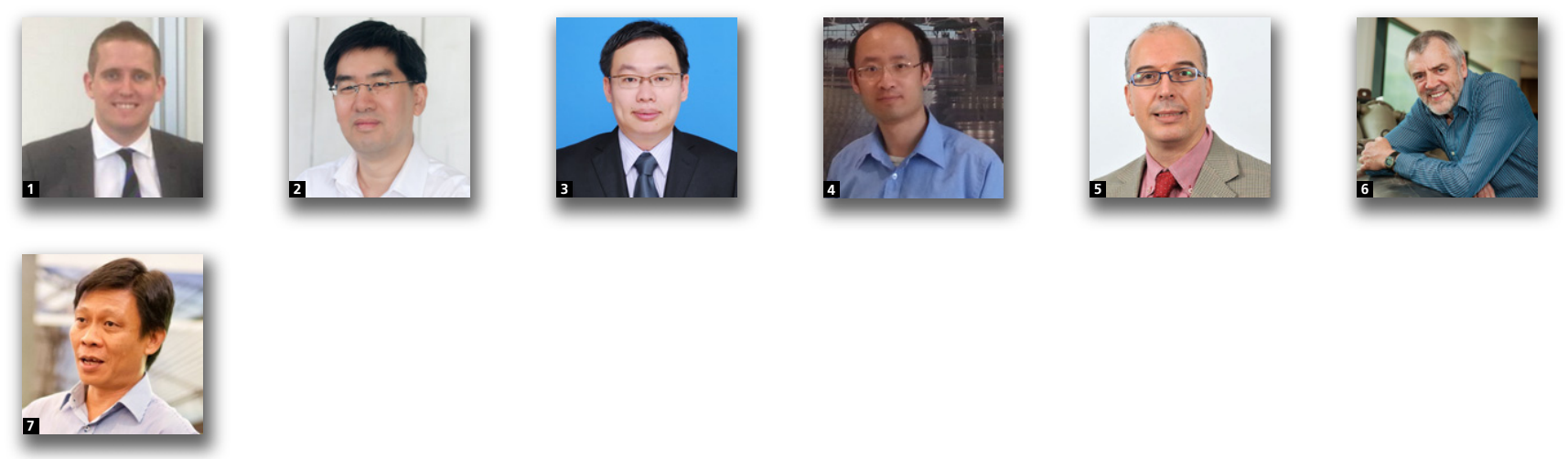

This paper presents the results of a full-scale site fire test performed on a cold-formed steel portal frame building with semi-rigid joints. The purpose of the study is to establish a performance-based approach for the design of such structures in fire boundary conditions. In the full-scale site fire test, the building collapsed asymmetrically at a temperature of $714^{\circ} \mathrm{C}$. A non-linear elasto-plastic finite-element shell model is described and is validated against the results of the full-scale test. A parametric study is presented that highlights the importance of in-plane restraint from the side rails in preventing an outwards sway failure for both a single portal and full building geometry model. The study also demonstrates that the semi-rigidity of the joints should be taken into account in the design. The single portal and full building geometry models display a close match to site test results with failure at $682^{\circ} \mathrm{C}$ and $704^{\circ} \mathrm{C}$, respectively. A design case is described in accordance with Steel Construction Institute design recommendations. The validated single portal model is tested with pinned bases, columns protected, realistic loading and rafters subject to symmetric uniform heating in accordance with the ISO 834 standard fire curve; failure occurs at $703^{\circ} \mathrm{C}$.

\section{Notation}

D web depth of channel section

$\begin{array}{ll}\varepsilon_{\text {true,p }} & \text { true plastic strain } \\ \sigma & \text { engineering stress } \\ \sigma_{\text {true }} & \text { true stress }\end{array}$

$I_{x x} \quad$ second moment of area about major axis

$I_{y y} \quad$ second moment of area about minor axis

$L \quad$ lip length of channel section

$t \quad$ thickness of channel section

$W \quad$ flange width of channel section

$\varepsilon \quad$ engineering strain

\section{Introduction}

Portal frames composed entirely of cold-formed steel (Figure 1) can be a viable alternative to conventional hotrolled steel portal frames for agricultural, light industrial and sports buildings (Lim and Nethercot, 2004). Research into the 


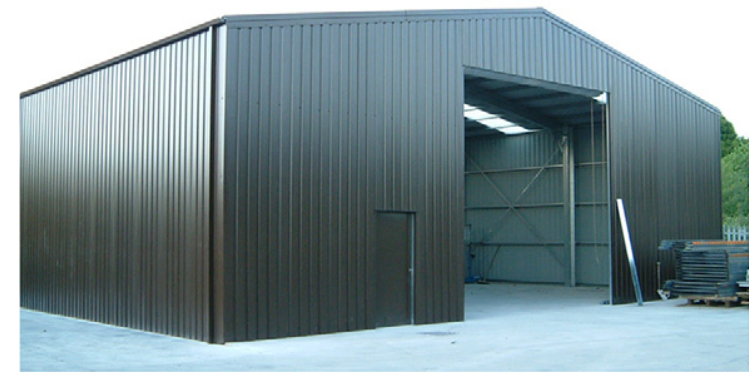

Figure 1. Typical cold-formed steel portal frame

development of cold-formed steel portal frames has been carried out by Chung and Lau (1999), Lim and Nethercot (2004), Mills and Laboube (2004), Dubina et al. (2004) and Rhodes and Burns (2006). Wrzesien et al. (2012) presents a full literature review of the work done on the design development of such frames.

Despite the increasing popularity of cold-formed steel portal frames, however, there is limited research on their collapse behaviour at elevated temperatures. Further research is required in order to ensure the prevention of fire spread as well as to protect the safety of occupants escaping and fire fighters who may be in close proximity to the building. As shown in Figure 2, ideally, an eventual inward collapse mechanism should take place, as opposed to an outward collapse mechanism (O'Meagher et al., 1992). The UK building regulations (HMG, 2006) make reference to the Steel Construction Institute (SCI) design method (Simms and Newman, 2002) for single-storey structures in fire boundary conditions. However, this design method is intended for the design of conventional hot-rolled steel portal frames. No current guidance exists specifically for the design of cold-formed steel portal frame structures in fire boundary conditions.

Currently the SCI design method allows the rafters to be left unprotected, so long as the column bases are designed to resist an overturning moment, calculated in accordance with the SCI design method. The SCI design method makes the assumption that both rafters are heated uniformly. It also assumes that the

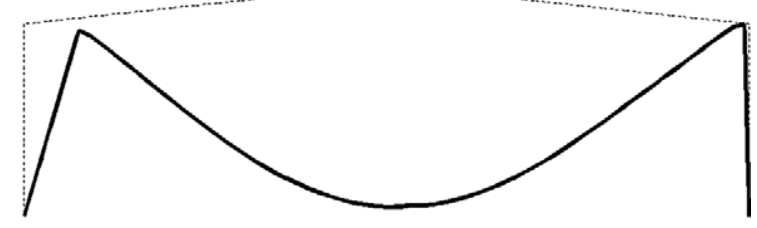

Figure 2. Collapse mechanisms after O'Meagher et al. (1992): (a) acceptable inward collapse mechanism; (b) unacceptable outward collapse mechanism rafters undergo a symmetrical inward snap-through-buckling collapse mechanism, after which the frame stabilises with the rafters suspended below the columns in catenary action.

Recent research on hot-rolled steel portal frames, however, indicates that the SCI design recommendations may not be adequate and that the frame may be susceptible to an asymmetric mode of collapse (Rahman et al., 2013). Wong (2001) conducted a fire test on a hot-rolled steel portal frame. Lateral stability to the test frame was provided by way of purlins to a gable frame. In the fire test, elevated temperatures were applied uniformly to the test frame through a tray of heptane fuel suspended below the rafters. The column bases were pinned. It was observed by Wong that, under the fire, the frame had a tendency to sway sideways. Bong (2005) extended the work of Wong, developing a beam model of a portal frame building arrangement that included purlins and side rails. An asymmetric sideways sway mode was observed. Again using a beam model, Song et al. (2009) modelled the frame tested by Wong and were able to predict the behaviour of the frame to collapse.

For the case of cold-formed steel portal frames, Pyl et al. (2012) conducted a full-scale test on a steel portal frame building with cold-formed steel members and hot-rolled steel gusset plates. The test building had an $8 \mathrm{~m}$ span, was $20 \mathrm{~m}$ long, with height to eaves of $2.5 \mathrm{~m}$ and a frame spacing of $5 \mathrm{~m}$ with column bases fixed to pad foundations. Back-to-back $230 \mathrm{~mm}$ deep sigma sections were used for columns and rafters with joints formed through hot-rolled steel brackets; the joints could therefore be assumed to function as rigid. Pyl et al. (2012) used insulated composite panels for the walls and roofing, with thicknesses of $120 \mathrm{~mm}$ and $100 \mathrm{~mm}$, respectively. The internal frames of the building were not therefore free to collapse independently of the cladding. Pyl et al. (2012) used stacked timber cribs for the fire source, placed and ignited evenly across the floor of the structure. A beam idealisation of the structure was presented, with restraint applied to the model at gable ends to try to capture the effect of diaphragm action from the cladding. No allowance in the beam idealisation was made for joint strength and stiffness.

Previous research has therefore indicated that the SCI design recommendations may not be conservative, as the frame may undergo an asymmetrical sideways collapse, as opposed to the symmetrical inwards collapse assumed by the SCI design guide. Furthermore, in order to develop a performance-based design approach for cold-formed steel portal frames, the fullscale building test reported by Pyl et al. may not be suitable, as the column and rafter members were restrained by the cladding, the stiffness of which was not established either at elevated or ambient temperature. In addition, the joints were formed through hot-rolled steel brackets; this is not the case for portal frames in the UK and Asia, which have brackets constructed from cold-formed steel. Finally, in terms of developing a numerical model to idealise the behaviour in fire, 
a beam model cannot capture the effects of plate buckling that eventually lead to failure.

The concerns outlined are addressed by the investigations in this paper. A full-scale natural fire test on a building constructed entirely of cold-formed steel is described for an $8 \mathrm{~m}$ span, height to eaves of $2 \cdot 155 \mathrm{~m}$, length of $10 \mathrm{~m}$ with a frame spacing of $2.5 \mathrm{~m}$. The cladding of the building was detailed to act independently of the frames, allowing for negligible diaphragm action to develop from the cladding. The results of the full-scale test are used to validate a non-linear elasto-plastic finite-element (FE) shell model, which can capture the effects of plate buckling. Both a single-portal frame model and a full building geometry model (including primary and secondary members) are described. The collapse temperature predicted by the numerical models is found to be similar to that of the full-scale test. The parametric study and full building arrangement model show the beneficial effect of the secondary members on the failure temperature and collapse mechanism. A realistic design scenario is described in which the rafters are subject to uniform heating in accordance with the ISO standard fire curve, with the columns protected and bases pinned. The importance of in-plane restraint from side rails is again demonstrated.

The numerical model is shown to be conservative; therefore, it can be used by engineers to assist in the design of such structures in fire boundary conditions. The investigation presented will form the basis of a performance-based approach for the design of cold-formed steel portal frames in fire boundary conditions.

\section{Full-scale test arrangement}

\subsection{Preamble}

The fire test was carried out at Curtin University, Sarawak Campus, Sarawak, Malaysia on 23 July 2013. The fire test was the result of international collaboration between Queen's University Belfast, Curtin University Sarawak, the University of Strathclyde and Ecosteel. Partial funding for the test was provided through an ICE research and development award, which is gratefully acknowledged. The planning of the tests used Revit building information modelling (BIM) to assist with communication, visualisation and instrumentation positioning (see Figure 3). The tests are summarised in Johnston et al. (2015), with full details provided herein.

\subsection{Details of building}

The frames used for the building had a span of $8 \mathrm{~m}$, height to eaves of $2 \cdot 2 \mathrm{~m}$ and pitch of $10^{\circ}$. The total length of the building length was $10 \mathrm{~m}$, comprising five frames spaced at $2.5 \mathrm{~m}$. Cold-formed steel channel sections were used for the entire building with a material grade of G550 steel. The section designation, nominal dimensions and section properties are shown in Table 1. The columns and rafters were constructed using

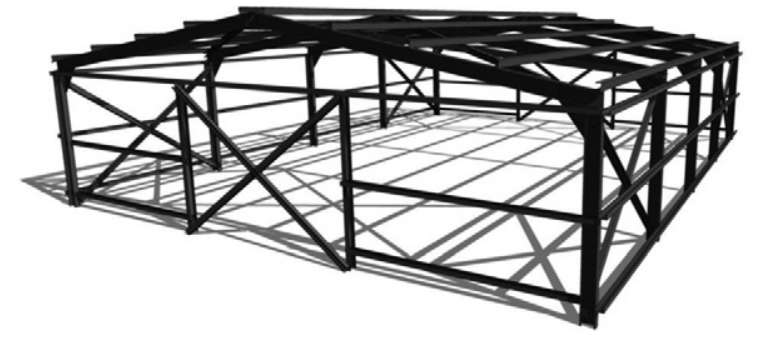

Figure 3. Revit BIM model used for collaboration

\begin{tabular}{lrcccccr}
\hline $\begin{array}{l}\text { Section } \\
\text { designation }\end{array}$ & $\begin{array}{c}D: \\
\mathrm{mm}\end{array}$ & $\begin{array}{c}W: \\
\mathrm{mm}\end{array}$ & $\begin{array}{c}L: \\
\mathrm{mm}\end{array}$ & $\begin{array}{c}T: \\
\mathrm{mm}\end{array}$ & $\begin{array}{c}\text { Area: } \\
\mathrm{cm}^{2}\end{array}$ & $\begin{array}{r}I_{x x}: \\
\mathrm{cm}^{4}\end{array}$ & $\begin{array}{r}I_{y y}: \\
\mathrm{cm}^{4}\end{array}$ \\
\hline $\mathrm{C} 15016$ & 150 & 60 & 18 & 1.6 & 4.57 & $160 \cdot 0$ & $22 \cdot 6$ \\
$\mathrm{C} 10012$ & 95 & 50 & 19 & 1.2 & 2.59 & $37 \cdot 7$ & 9.9 \\
C07510 & 75 & 40 & 15 & 1.0 & 1.70 & $15 \cdot 4$ & $4 \cdot 1$
\end{tabular}

Table 1. Section properties of cold-formed steel channel sections

C15016 lipped channel section, which denotes a section having $150 \mathrm{~mm}$ web depth and $1.6 \mathrm{~mm}$ thickness. The gable end frames used $\mathrm{C} 10012$, and the purlin, side rails and bracing members used C07510 sections.

The eaves and apex joints were formed through a $400 \mathrm{~mm} \times$ $450 \mathrm{~mm}$ cold-formed steel plate with thickness of $3 \mathrm{~mm}$. Each joint comprised two rows of $10 \times 5.43 \mathrm{~mm}$ diameter AS Tek self-drilling fasteners, each with a length of $20 \mathrm{~mm}$. Further details on the screw fasteners are given in Table 2. The column bases were pinned using an M25 bolt through a $5 \mathrm{~mm}$ thick steel base cleat. An isolated $700 \times 700 \times 400 \mathrm{~mm}$ pad foundation was used under each column.

The cladding comprised $9 \mathrm{~mm}$ thick cement board, which was detailed in such a manner as not to contribute to diaphragm action. This was achieved through the cladding material itself, the boards not being placed overlapped and the screw

\begin{tabular}{ll}
\hline Fastener description & XT12 - 14 × 20 mm \\
Diameter & Gauge \#12 $(5.43 \mathrm{~mm})$ \\
Thread form & 14 threads per inch \\
Drive & Hex head $5 / 16$ inch \\
Length & $20 \mathrm{~mm}$ \\
Drill point & $6.0 \mathrm{~mm}$ length $/ 4.50 \mathrm{~mm}$ diameter \\
Type of steel & C1022 steel, hardened, heat treated \\
Single shear & $9.0 \mathrm{kN}$ \\
Torsion & $13 \mathrm{~N} \mathrm{~m}$
\end{tabular}

Table 2. Details of fastener specification 
connections being semi-rigid and limited in number. An opening $2.5 \mathrm{~m}$ wide by $1.9 \mathrm{~m}$ high was placed at both gable end frames to simulate a roller shutter door. Along the side of the structure, four openings, each $0.6 \mathrm{~m}$ wide and $0.875 \mathrm{~m}$ high, were included. The size of the openings was designed to ensure that there would be sufficient ventilation, without which the fire may have extinguished prematurely.

\subsection{Loading, fire source and instrumentation}

A load equal to $0 \cdot 545 \mathrm{kN} / \mathrm{m}$ was applied to the roof. The load comprised self-weight of the members, cladding, purlins and the applied the weight of the cement brick. The additional cement brick load was to ensure collapse of the frame would occur during the fire, to enable subsequent validation of advanced structural models. The load was applied through a $9 \mathrm{~mm}$ thick cement board, supported by purlins spanning between adjacent frames.

Timber cribs were stacked to a height of $1.4 \mathrm{~m}$ across the entire base of the structure, except for a $1.0 \mathrm{~m}$ corridor where the fire was ignited. The total volume of wood was recorded as

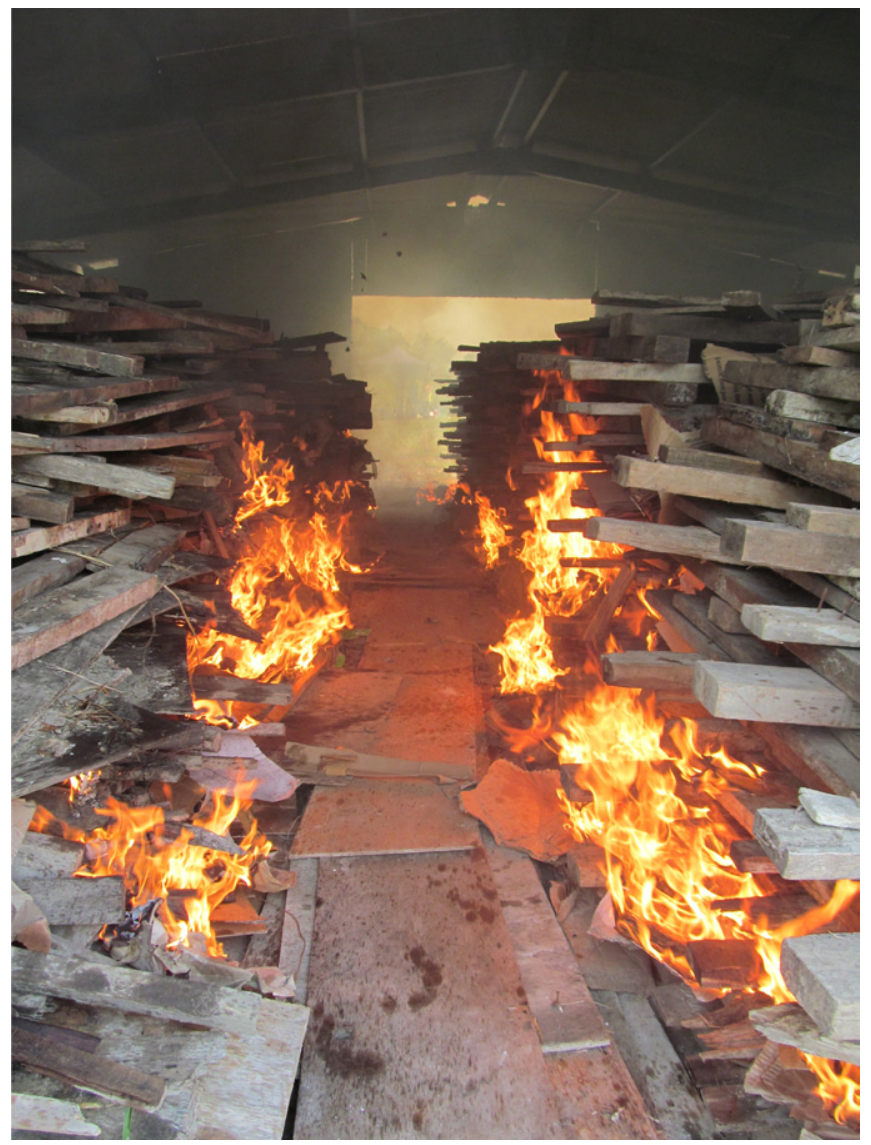

(a)
$47 \mathrm{~m}^{3}$, with a unit weight of $670 \mathrm{~kg} / \mathrm{m}^{3}$. The calorific value of the timber was $16000 \mathrm{~kJ} / \mathrm{kg}$.

Instrumentation to measure steel temperature and displacement were positioned at critical positions around the structure. A centralised timing system was employed where readings for each instrument were taken and recorded at $15 \mathrm{~s}$ intervals. Type $\mathrm{K}$ thermocouple wire was used with eight thermocouples connected to the structure. Two laser range measuring devices were used to measure and record the displacement of the columns on the central portal frame. The cladding was removed locally to expose the steel structure and measurements were taken on the outside flange of the column at a height of $1.8 \mathrm{~m}$ from the base.

\section{Full-scale test results}

\subsection{Temperature development}

The timber was lit at the base of the cribs on one side of the span only, in order to attempt to initiate a non-uniform natural fire within the building. Figure 4(a) shows the ignition stage of the fire, at a time of $90 \mathrm{~s}$ from ignition.

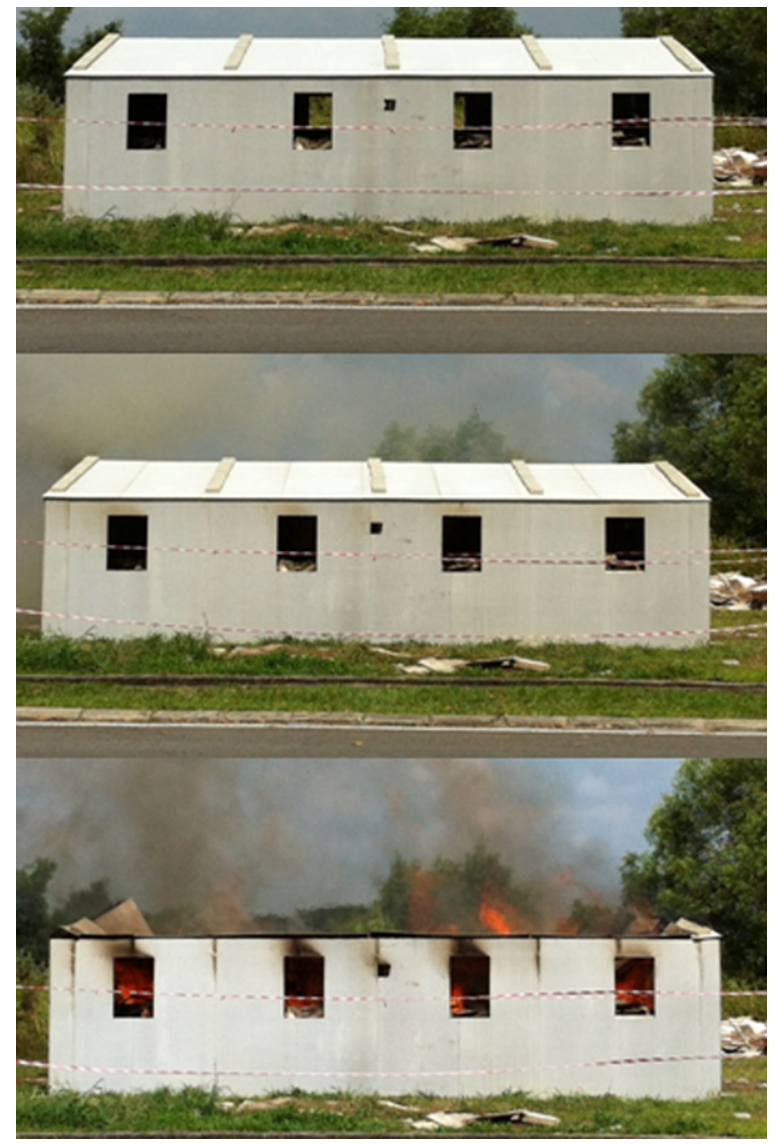

(b)

Figure 4. Photographs from full-scale site test: (a) ignition stage (time $=90 \mathrm{~s}$ ); (b) side view showing initial state, state during fire and post collapse 
Figure 4(b) shows photographs taken from the site test. The top image of the row of three shows the initial state of the building prior to ignition. The middle image shows the building under the initial stages of the fire; smoke is evident from the gable end. The bottom image shows the instance when the roof collapses. Note the square hole in the side cladding to allow displacement measurement of the column steel section.

Figure 5 shows the variation of temperature against time for each of the eight thermocouples placed around the structure. The standard ISO time-temperature curve, hydrocarbon curve and parametric nominal time-temperature curve are also shown for comparison. The parametric curve was developed using the building geometry, openings and fire source. Although not strictly comparable, owing to the significant period of fire development encountered in the full-scale test and the fact that the standard curves start at/or near to flashover, the chart enables assessment of the temperature-time gradients. As can be seen, the thermocouples show a slow initial

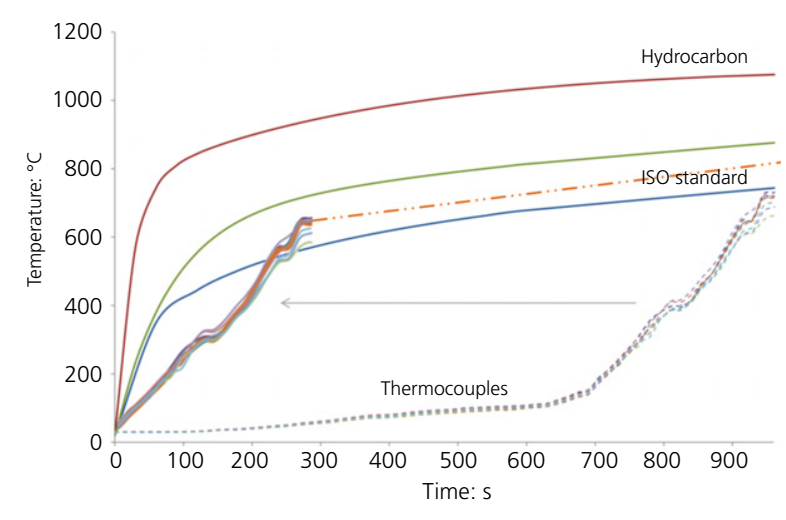

Figure 5. Variation of time against temperature recorded from thermocouples with assumed growth period of post collapse growth up to $720 \mathrm{~s}$ ( or $200^{\circ} \mathrm{C}$ ), after which the fire growth develops rapidly with a gradient comparable to the initial slope of the nominal fire curves. For ease of comparison against the standard ISO curve, the thermocouple curves have been offset along the $x$-axis.

The thermocouple wire provided the temperature distribution of eight locations around the structure until the point of collapse. A limitation of the experimental set-up was that, when the structure collapsed, the screwed connections attaching the thermocouple wire to the steel members failed; readings taken after this point were therefore not valid.

\subsection{Description of collapse}

Figure 6 shows a graphical representation of the central portal frame behaviour, comparing displacement of the frame with time from ignition. As can be seen, the collapse mode was asymmetric, with initial thermal expansion of the frame followed by an inward collapse at $714^{\circ} \mathrm{C}$, at a time of $16 \mathrm{~min} 15 \mathrm{~s}$ from ignition.

Figure 7(a) shows a photograph of the asymmetric collapse of the cold-formed steel structure during the fire. Figure 7(b) shows a photograph of the frame after the fire, in which the buckling of the structural members is evident. Neither the eaves nor the apex screwed joints failed. Instead, failure occurred through buckling in the channel sections, at a distance offset from the joints along the member length.

The top side rails at eaves level were observed to undergo buckling along their length, before collapse; no lateral restraint could therefore be provided by the top side rails. On the other hand, the middle and bottom side rails had a higher degree of shielding from the fire and so did not buckle as early. In addition, the cold-formed steel strap that provided restraint to the compression flange of the column underwent large deformation and warping.

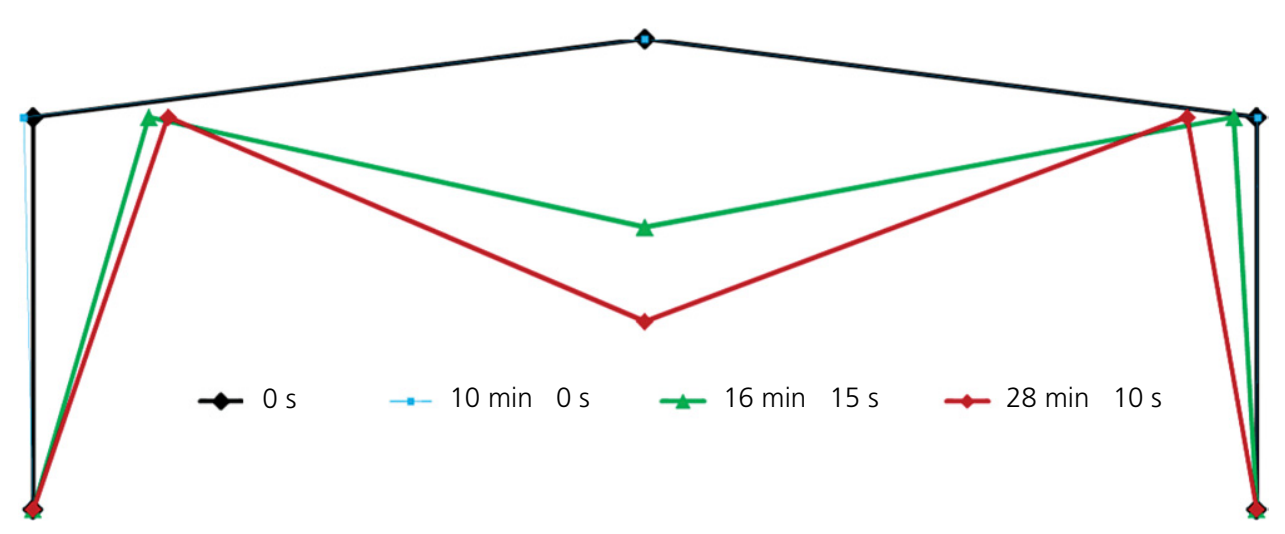

Figure 6. Graphical representation of central portal frames collapse from full-scale test 


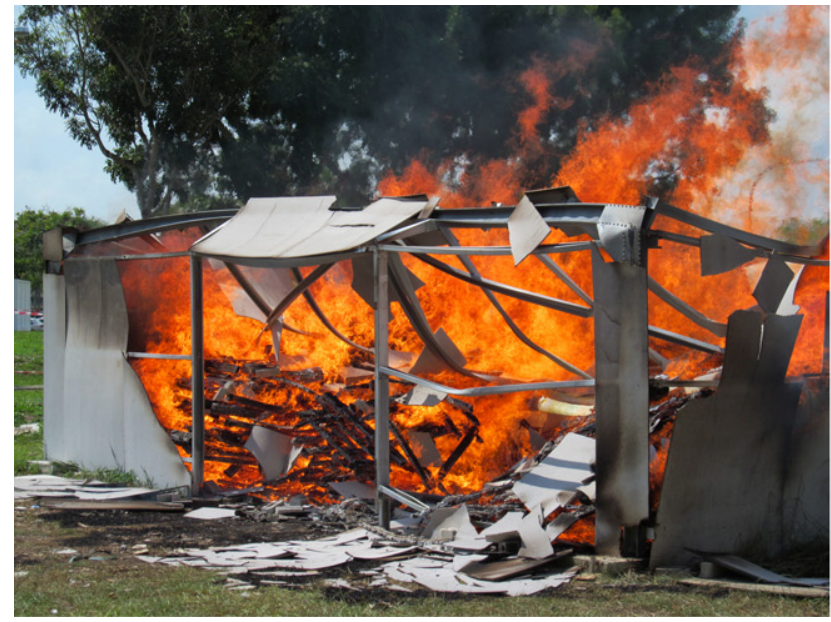

(a)

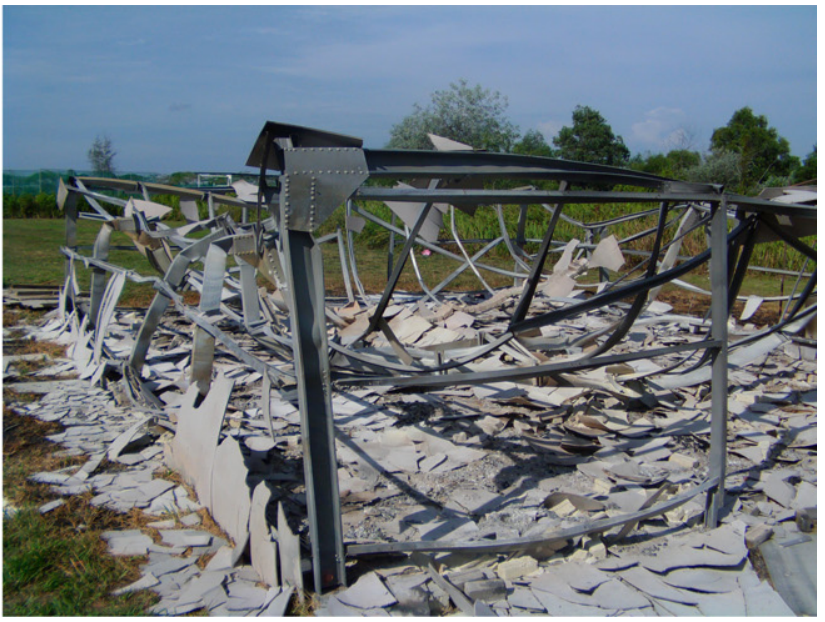

(b)

Figure 7. Photographs from full-scale site test: (a) frame collapse; (b) final deformed shape

Figure 8 shows the variation of lateral eaves displacement of the column at eaves level against temperature for the left-hand side (LHS) and right-hand side (RHS) columns of the central portal. Initially, the temperature of the cold-formed steel rafter and column increased due to the fire. This heating of the steel caused expansion and resulted in the columns moving laterally outwards at the eaves level (as observed by a negative value on the chart). This is true up to $714^{\circ} \mathrm{C}$, with a maximum measured outwards rotation of $3^{\circ}$. The reduced strength and stiffness of the steel then caused the cold-formed steel channel section to buckle, which led to a sharp asymmetrical inwards movement due to rafter collapse. The behaviour of the columns and rafter can be seen as asymmetrical, which can be expected since the fire was non-uniform.

\section{Non-linear FE analysis}

\subsection{Preamble}

In this section, a non-linear elasto-plastic implicit dynamic analysis of the cold-formed steel portal frame is described. This model of the full-scale test frame employed shell elements for the channel sections and brackets, and connector elements to represent the screwed connections and the effects of bolthole elongation caused by the bearing of the screws against the brackets. Contact was modelled between channel sections and brackets. The purpose of the FE analysis is to validate a numerical model against the results of the full-scale test, for purposes of establishing a parametric study to investigate the behaviour of such frames. Johnston et al. (2014) previously

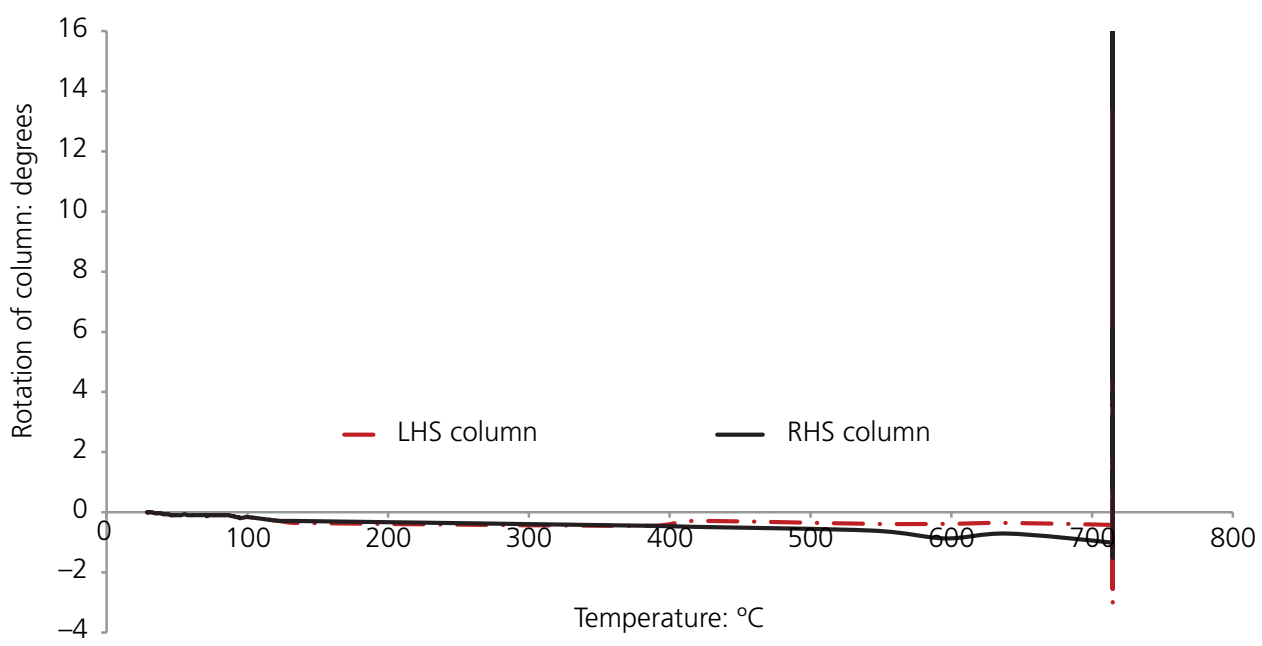

Figure 8. Variation of column rotation against temperature 
carried out a benchmark study to compare varying types of analysis for cold-formed steel portal frames. Results demonstrated that FE shell models, with inclusion of geometric and material non-linearity, should be used over beam models. Initial geometric imperfections in the cold-formed steel members were not modelled. Although further work is intended to include the effect of these initial imperfections, Sabbagh et al. (2013) reported that the effect of such imperfections is minimal.

As described in section 3, it was observed from the full-scale site test that none of the screw connections connecting primary members failed. It was also observed that the top side rails buckled early within the fire and therefore did not offer full inplane and out-of-plane restraint. Therefore, in the initial FE validation model, a rigid connector was used to idealise the screw connections, with in-plane restraint being included at the location of the bottom two side rails only.

\subsection{Analysis type}

The frame was analysed using the general purpose FE program Abaqus v6.13-1. The analysis of the frame was conducted in two steps. First, a static general solver was used to apply boundary conditions and loading to the structure. The loading and boundary conditions were subsequently propagated to a second 'temperature step'. In this step an implicit dynamic solver was used to model the effects of elevated temperature.
A quasi-static application procedure was used within the implicit dynamic solver to regularise unstable behaviour. Such application settings adjust numerical settings (such as damping and time increments) to capture most efficiently and accurately the intended behaviour of the analysis. In a quasi-static application, inertia effects are introduced primarily to regularise unstable behaviour in analyses whose main focus is a final static response. Large time increments are taken when possible to minimise computational cost, with numerical dissipation used to obtain convergence.

\subsection{Modelling of fire and material properties}

The thermocouple data obtained from the full-scale fire test was applied to the FE model. The temperature against time amplitudes were applied to the structure using predefined fields and linked to temperature-dependent material properties and screw connector stiffness.

The mechanical properties of cold-formed steel at elevated temperatures have been investigated by Outlinen (1999), Lee et al. (2003), Mecozzi and Zhao (2005), Chen and Young (2007) and Ranawaka and Mahendran (2009). Each of these researchers carried out experiments based on tensile coupon tests at elevated temperature.

In this paper, the material model of Ranawaka and Mahendran (2009) was adopted. The engineering stress-strain curves at different temperatures are shown in Figure 9.

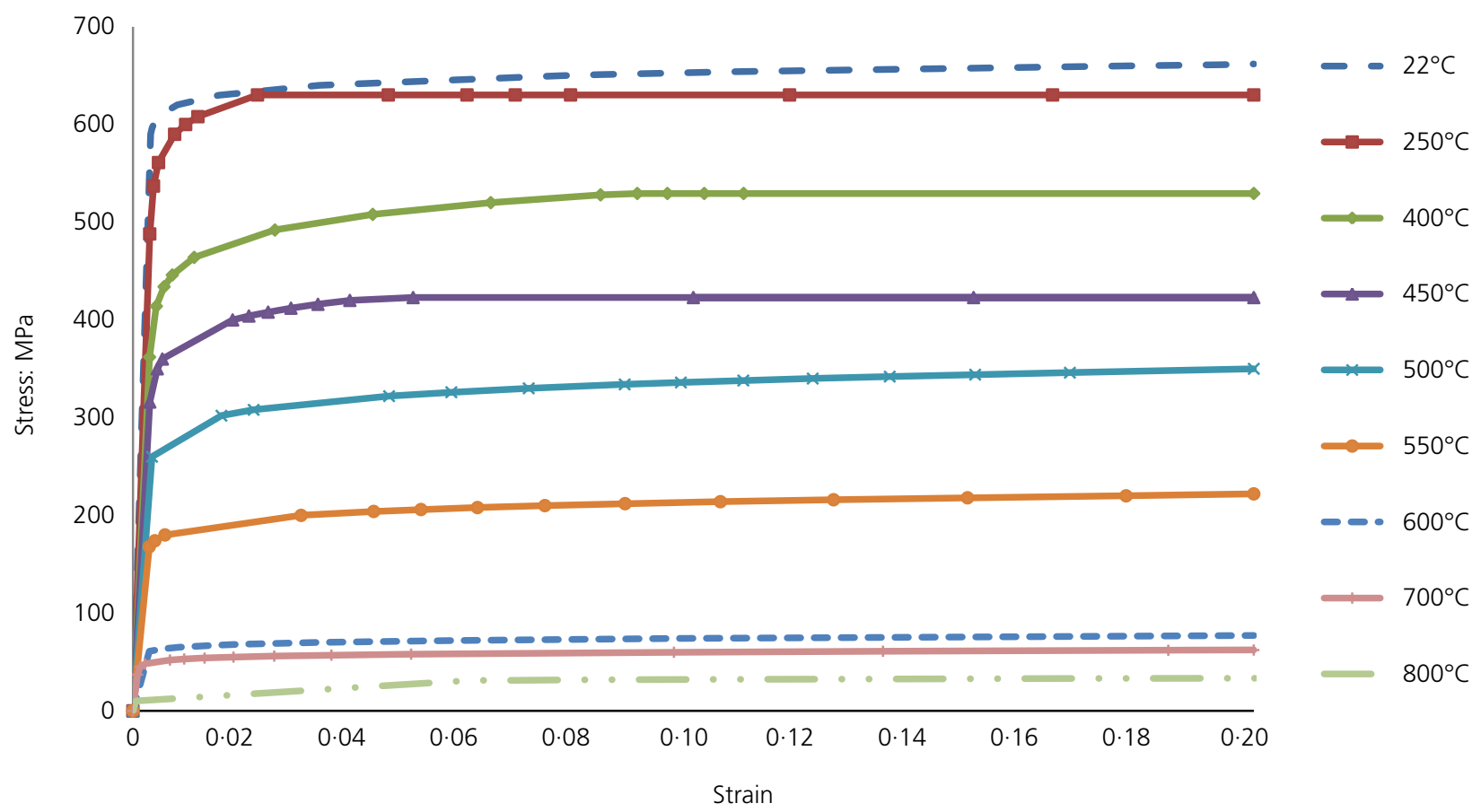

Figure 9. Engineering stress-strain curves at different temperatures after Ranawaka and Mahendran (2009) 
The value of Young's modulus used at ambient temperature was $210 \mathrm{kN} / \mathrm{mm}^{2}$, with appropriate reduction factors applied at elevated temperatures. A constant value of Poisson ratio of 0.3 was used. In addition to elastic and plastic properties at elevated temperatures, the effect of conductivity, thermal expansion and specific heat were included in accordance with Eurocode 3 (BS EN 1993-1-2 (BSI, 2005)) as was adopted by Rahman et al. (2013).

Abaqus requires the true stress-strain curves. In accordance with the Abaqus manual (Dassault Systèmes, 2013), for each temperature the true stress and true plastic strain were converted from the engineering stress and engineering strain as follows

\section{1. $\sigma_{\text {true }}=\sigma(1+\varepsilon)$}

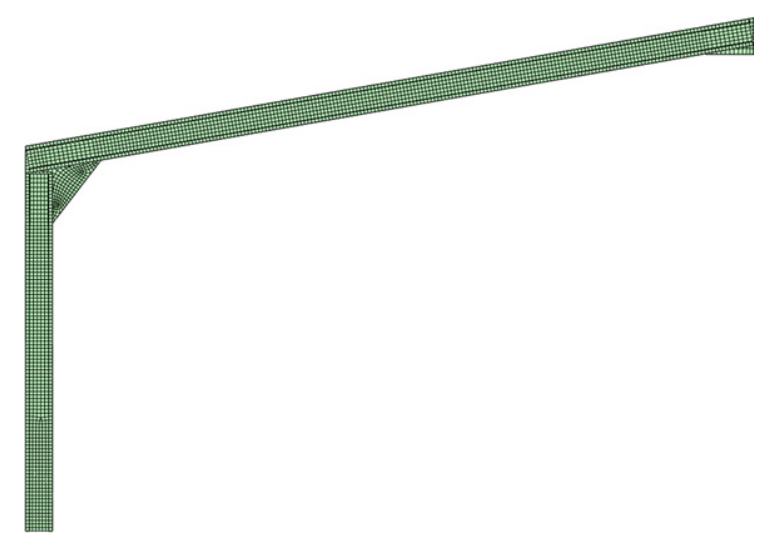

Figure 10. Details of FE mesh, mesh on geometry
2. $\varepsilon_{\text {true }, \mathrm{p}}=\ln (1+\varepsilon)-\sigma_{\text {true }} / E$

\subsection{Details of FE mesh}

Figure 10 shows the FE mesh of the test frame model. Figure 11 shows the mesh sensitivity study. As can be seen, the difference in collapse temperature for mesh sizes of $20 \mathrm{~mm}$ and $10 \mathrm{~mm}$ was found to be negligible. Both the channel sections and brackets were meshed with a maximum element size of $20 \mathrm{~mm} \times 20 \mathrm{~mm}$ to save on computational time.

The Abaqus shell element S4R was used. This element is a four-node doubly curved thin or thick shell, with reduced integration, hourglass control and finite membrane strains, and has previously been used for analysis of cold-formed steel structures, among others by Pham and Hancock (2010). The S4R element uses three translation and three rotational degrees of freedom at each node. The element accounts for finite membrane strains and arbitrarily large rotations. It is therefore suitable for large strain analyses and geometrically non-linear problems. Simpson's rule is used for thickness integration, with five integration points through the thickness of the sections and brackets. The entire model contained a total of 10853 quadrilateral elements.

Neither the screws nor holes were physically modelled. Instead, Abaqus connector elements were used to represent the effects of elongation of the holes. The use of the connector elements enabled direct input of the elongation stiffness of each screw connection. At the joints, contact was defined between the webs of the channel sections, and also between the brackets and channel sections.

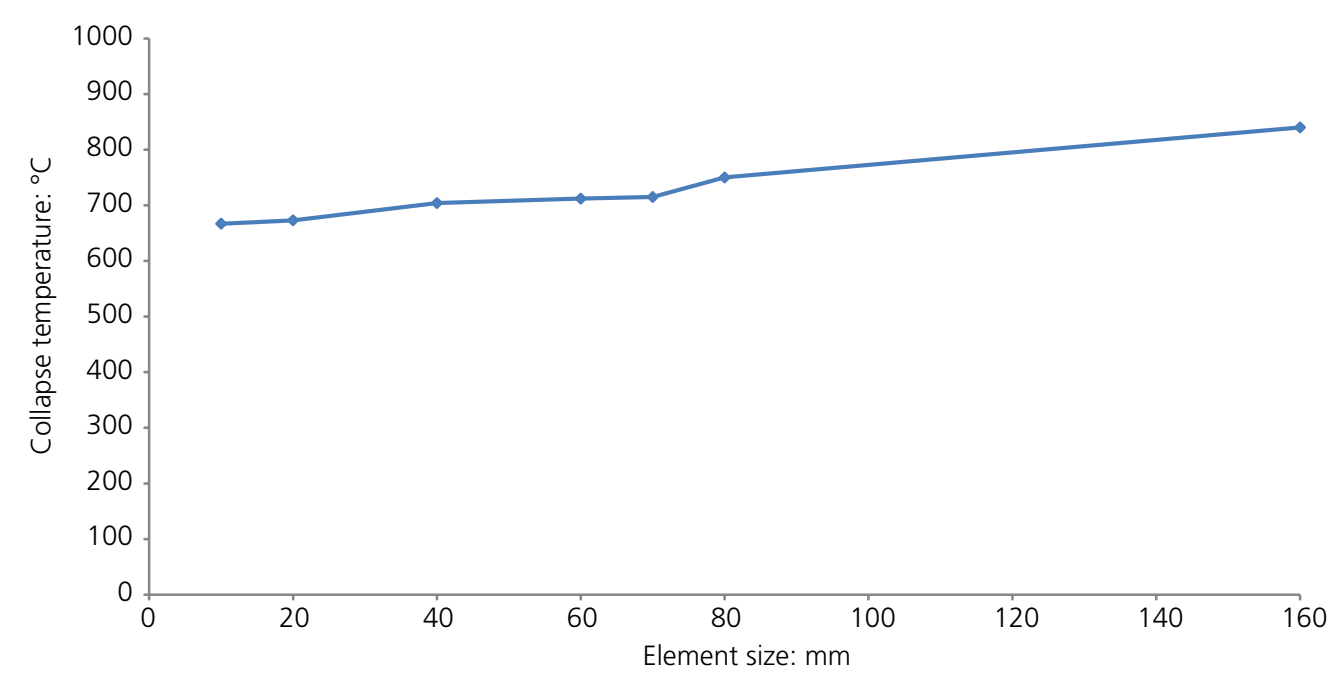

Figure 11. Mesh sensitivity study 


\subsection{Non-linear FE results}

Figure 12(a) shows the variation of lateral column displacement against temperature for the non-linear finite-element analysis (NLFEA) models. As can be seen, the columns initially rotate outwards owing to expansion of the steel.
After the rafter collapses, the columns collapse inwards, as was also observed in the full-scale test. The collapse temperature of the NLFEA model was $682^{\circ} \mathrm{C}$, which is comparable with the collapse temperature of $714^{\circ} \mathrm{C}$ from the full-scale test.

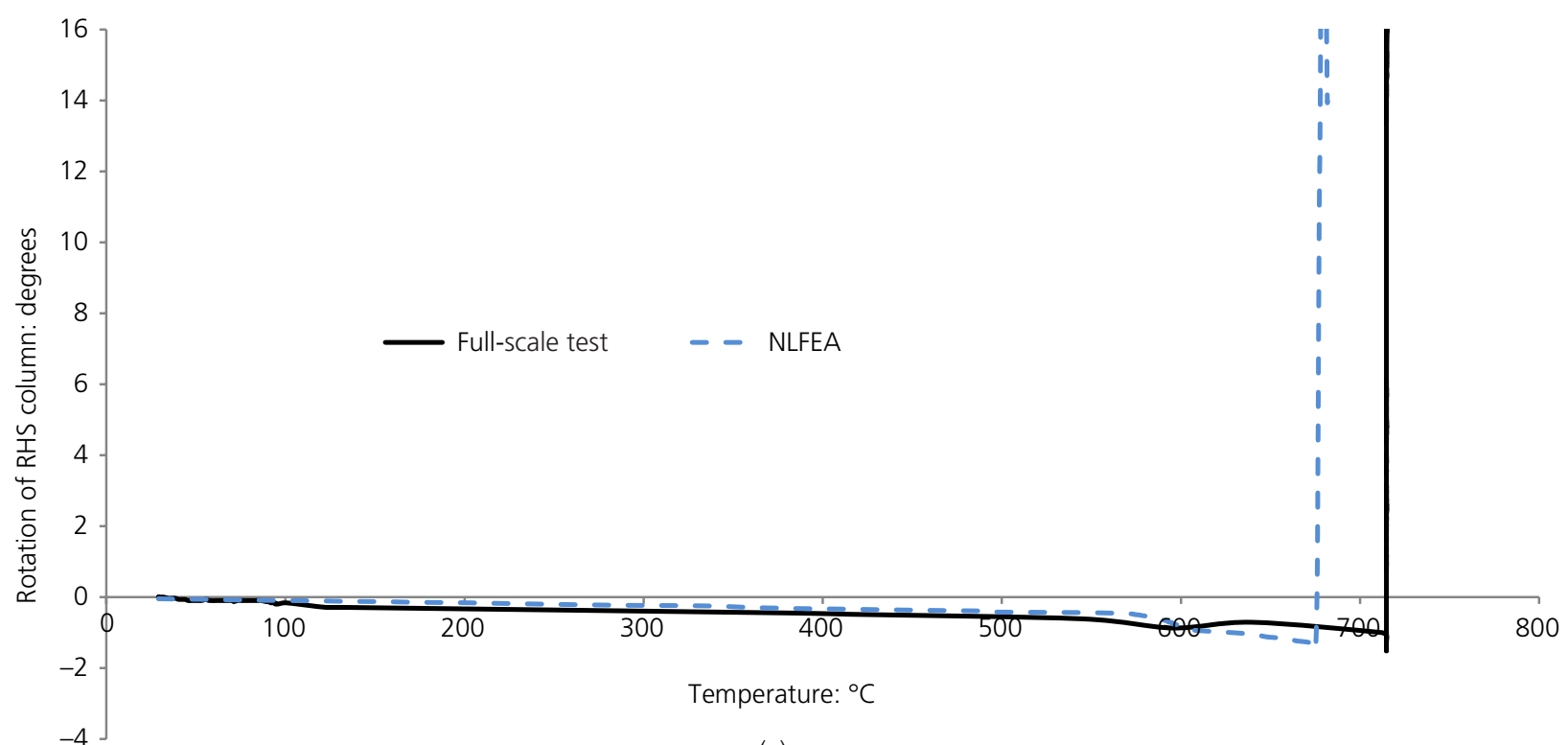

(a)

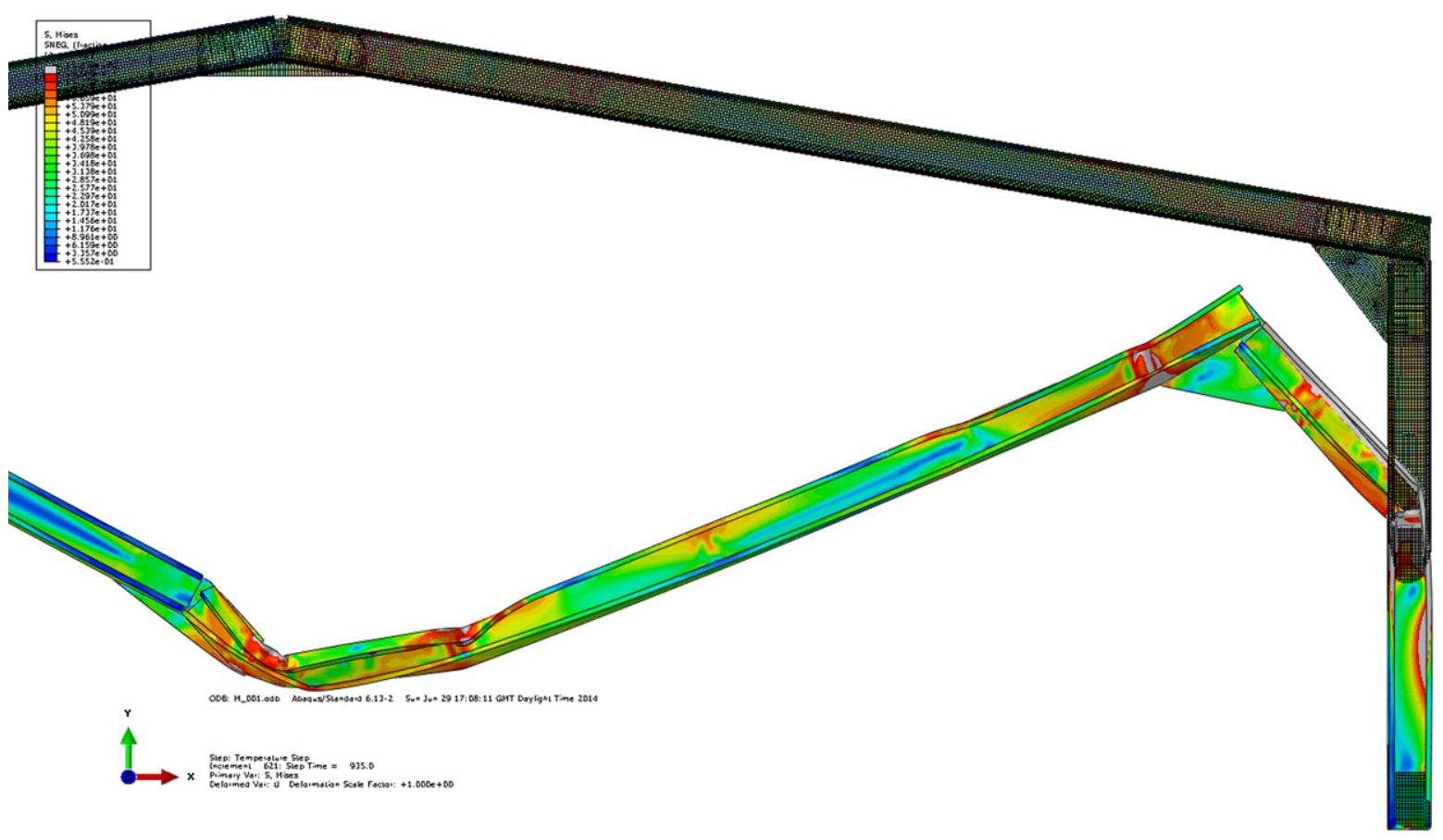

(b)

Figure 12. Behaviour of FE shell model: (a) variation of column rotation against temperature; (b) deformed shape of idealisation at $682^{\circ} \mathrm{C}$ 
Figure 12(b) shows the final deformed shape of the model. Half the model is shown for clarity. As can be seen, the asymmetric inwards failure mechanism and member buckling is similar to that of the full-scale site fire test. Figure 13(a) shows the deformed shape from the FE analysis; as can be seen, it is similar to that of the photograph of the eaves joint taken from the full-scale test after collapse (Figure 13(b)). Figure 13(c) and 13(d) shows the deformed shape in the vicinity of the eaves and apex joints, respectively.

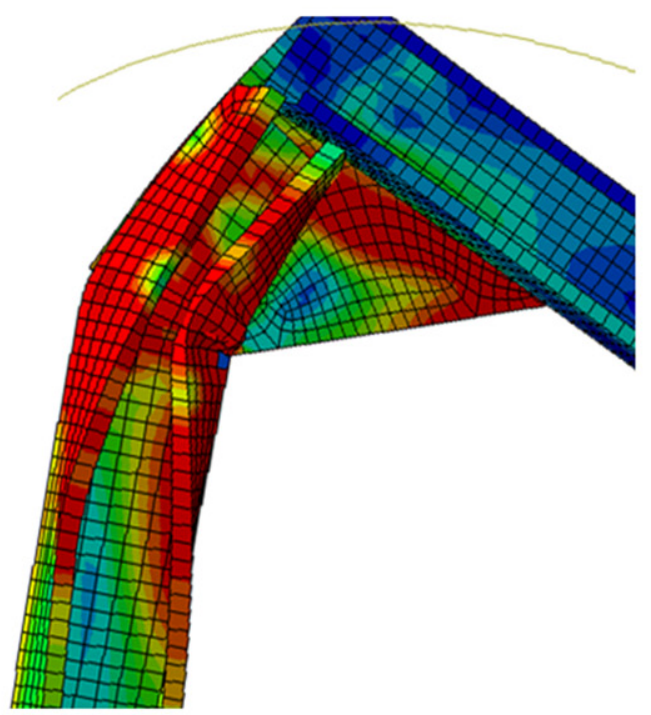

(a)

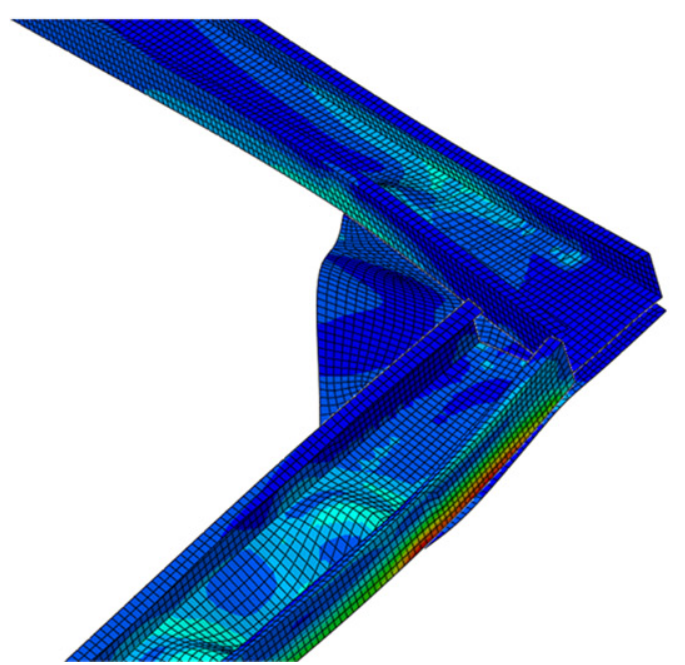

(c)

\section{Parametric study}

\subsection{Preamble}

In this section, a parametric study is presented that investigates the effect of in-plane restraint, joint stiffness and fire boundary condition design in accordance with current UK practice which uses the SCI design guidance. In addition, a full building arrangement model is presented that incorporates both primary and secondary members.

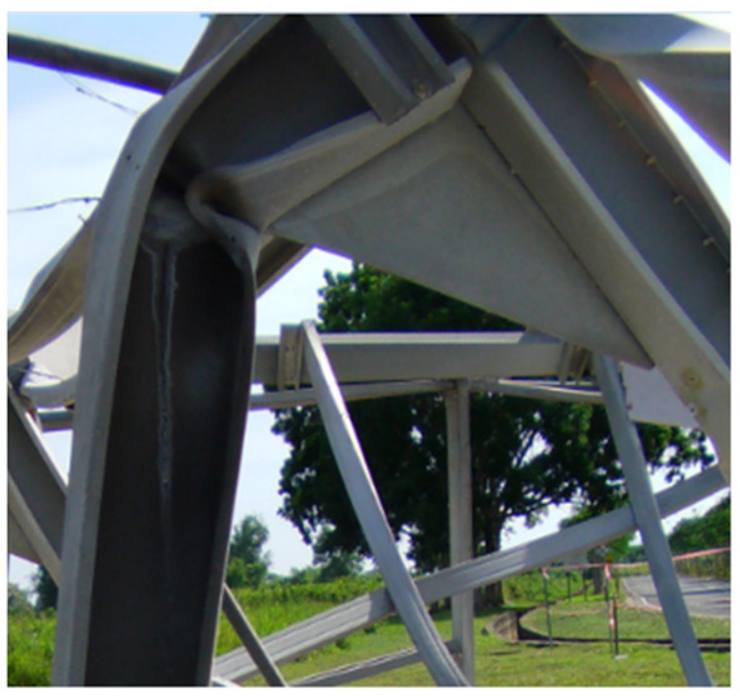

(b)

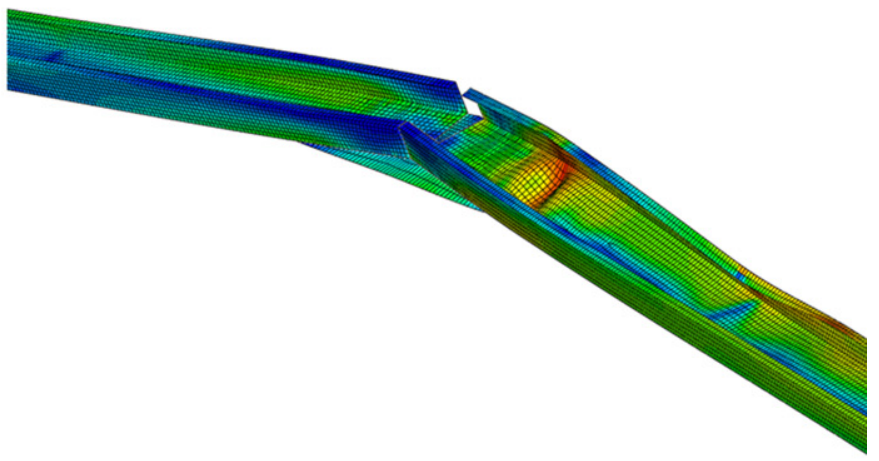

(d)

Figure 13. Buckling of cold-formed steel members: (a) FE; (b) full-scale test; (c) in vicinity of eaves joint; (d) in vicinity of apex joint 


\subsection{Effect of in-plane restraint from side rails}

The effect of in-plane restraint from the side rails is shown in Figure 14. As can be seen, when the model included restraint from all three side rails, the frame did not collapse before the $714^{\circ} \mathrm{C}$ collapse temperature recorded from the site test. When restraint from the bottom two side rails only was modelled, the frame failed at $682^{\circ} \mathrm{C}$ with an eventual inwards collapse mechanism. When restraint was provided at the bottom side rail only, the frame failed at $607^{\circ} \mathrm{C}$ in an eventual inwards collapse mechanism. For this condition, the frame did sway outwards for a period, prior to the rafter collapse that pulled the columns inward. When no in-plane restraint was modelled, the model failed at $582^{\circ} \mathrm{C}$, with the frame collapsing sideways with a full sway failure mechanism.

\subsection{Effect of joint stiffness}

In the full-scale tests it was observed that screws in the joints did not fail. This may be because often the connection is at a lower temperature than that recorded along the steel member (Kallerova et al., 2009). The FE model described in section 4 therefore assumed that the connector elements were infinitely rigid. It is known, however, that cold-formed steel joints are semi-rigid. In order to investigate the effect of joint flexibility, the FE model described in section 4 was re-analysed using a constant in-plane connector stiffness of $0.9 \mathrm{kN} / \mathrm{mm}$, extracted from graphical results presented by Kallerova et al. (2009). The same model was then re-analysed with a reduction factor applied due to effects of elevated temperatures, in accordance with reduction factors proposed by Yan and Young (2012) (see Figure 15(a)).
Figure 15(b) shows the effect of joint semi-rigidity on the collapse temperature. As can be seen, including the semirigidity of the joints reduces the collapse temperature by $36^{\circ} \mathrm{C}$, compared with the fully rigid assumption. However, including the effects of elevated temperatures (using the proposed reduction factors from Yan and Young (2012)) reduces the collapse temperature of the structure by just $3^{\circ} \mathrm{C}$.

\subsection{Effect of $\mathrm{SCl}$ design recommendations}

The effect of SCI design recommendations is presented, which incorporate current UK practice for single-storey steel structures in fire boundary conditions. Columns were assumed to be protected, with rafters subjected to uniform heating in accordance with the ISO standard curve. The rafter load applied was $0 \cdot 210 \mathrm{kN} / \mathrm{m}^{2}$ (or $0.525 \mathrm{kN} / \mathrm{m}$ ), to allow for cladding, insulation, purlins and reduced service load. A column load of $0 \cdot 16 \mathrm{kN} / \mathrm{m}^{2}$ was applied to include the self-weight of the side rails and wall cladding.

Initially, a model with pinned bases and in-plane restraint was investigated. Figure 16(a) shows the rafter of the model subject to elevated temperatures, with locations of yielding evident along the member at a temperature of $704^{\circ} \mathrm{C}$. Figure $16(\mathrm{~b})$ shows the deformed shape of the complete model geometry. During collapse, the rafters were held in catenary action with the rafter effectively becoming a tension member. As the steel continued to lose strength and stiffness, the tensile force in the rafters eventually caused the frame to collapse inwards. It was found that the SCI design recommendations had a small effect on the failure temperature. From Figure 17, the SCI design model with in-plane restraint collapsed at a temperature of

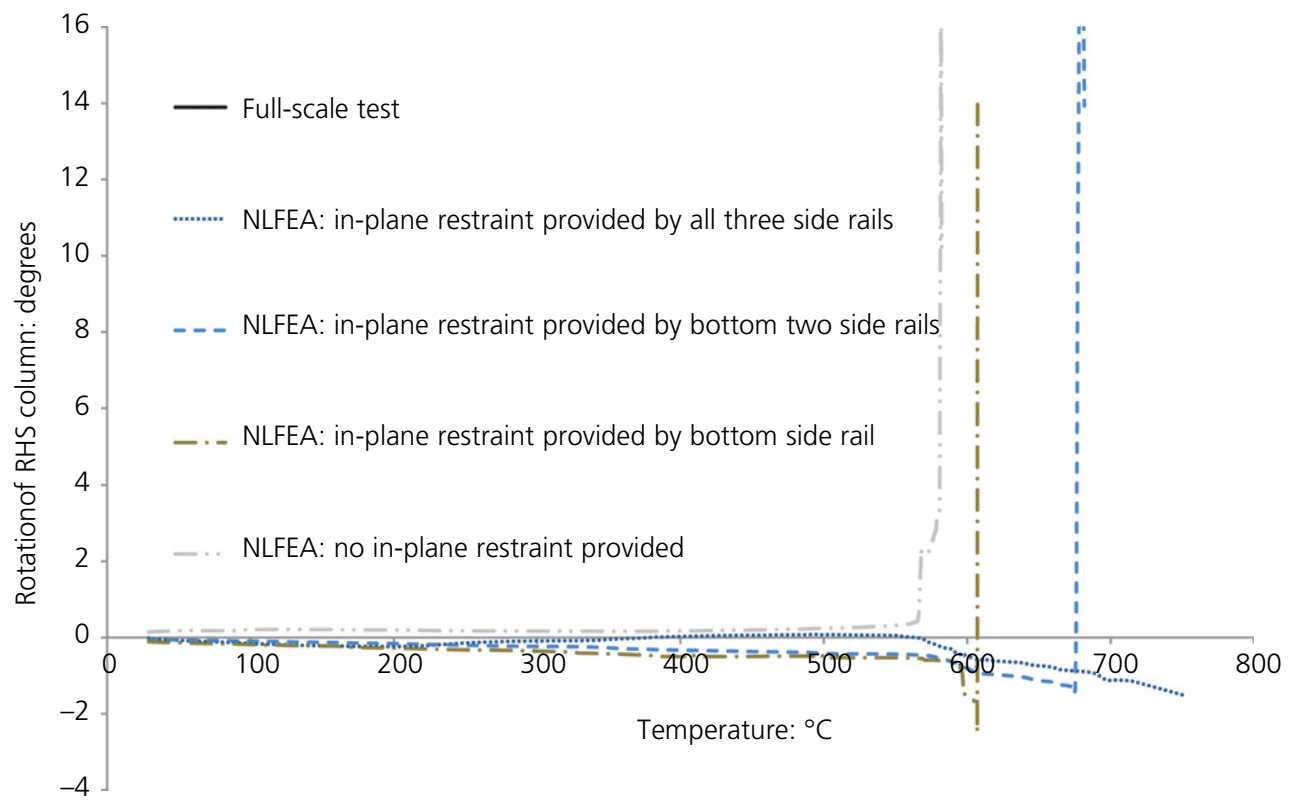

Figure 14. Effect of in-plane restraint provided by side rails 


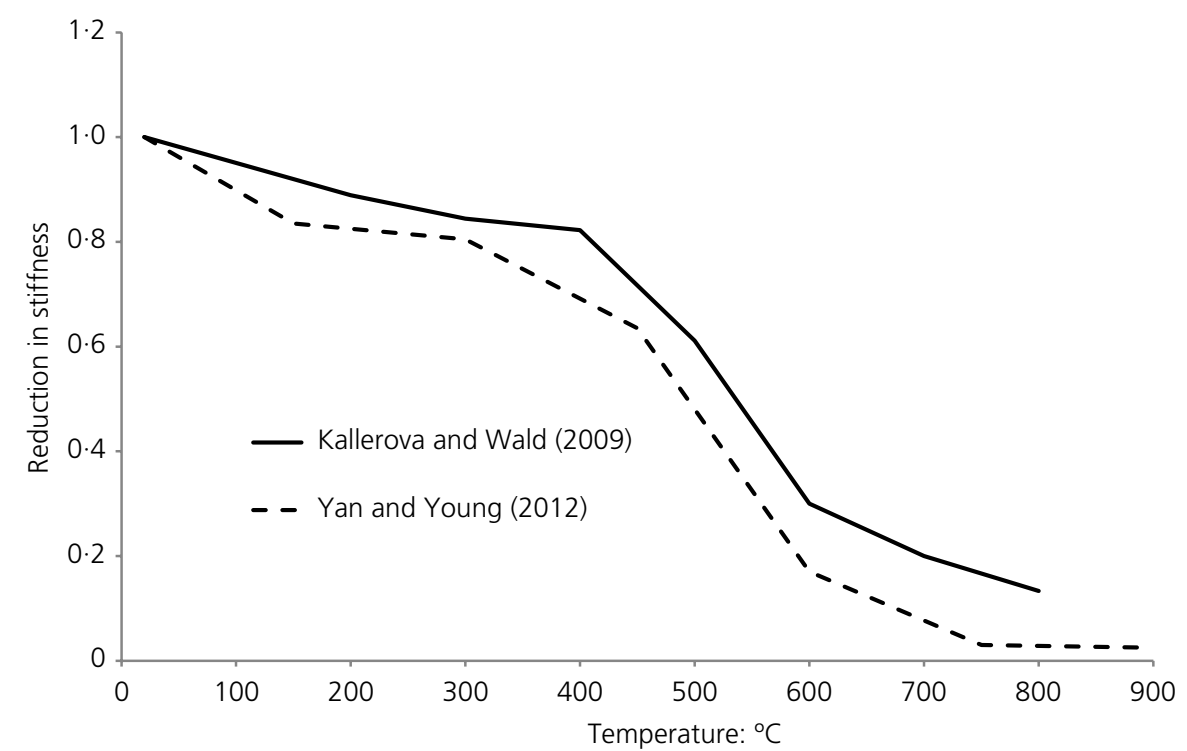

(a)

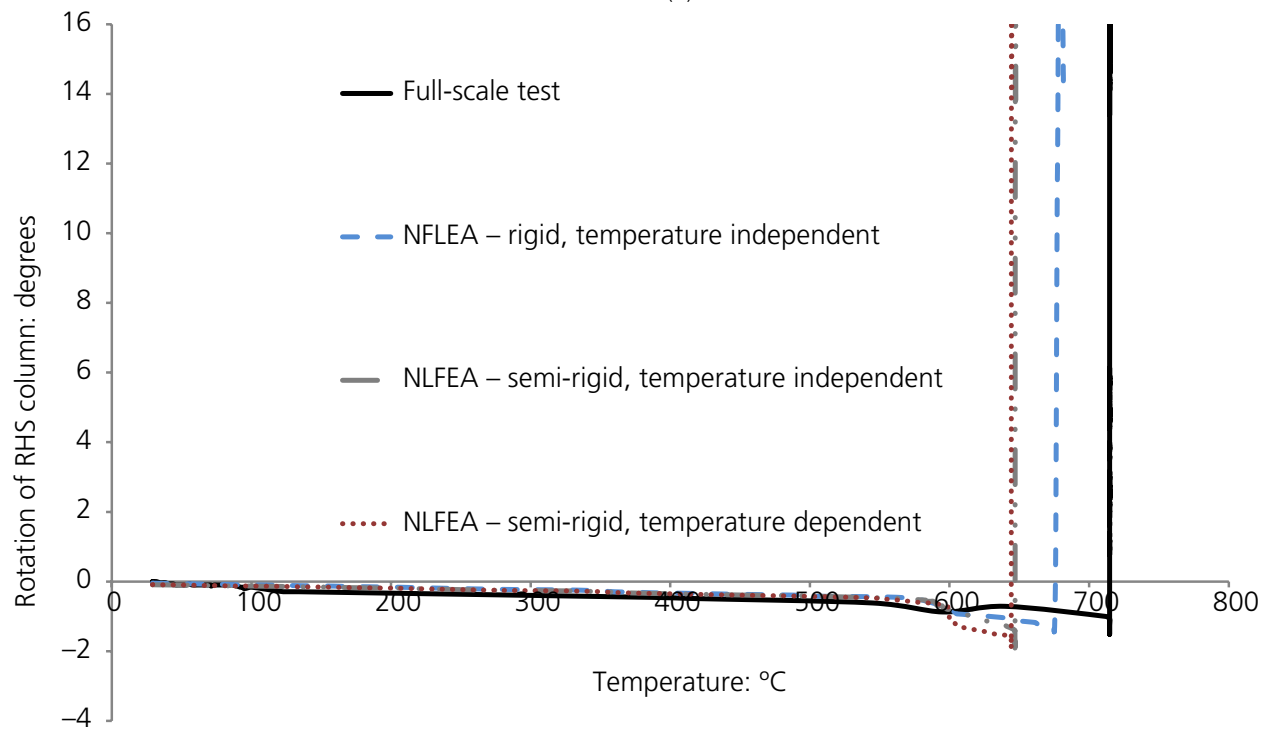

(b)

Figure 15. Investigation into effect of joint stiffness: (a) variation in reduction of bolt-hole elongation stiffness against temperature; (b) effect of joint rigidity on collapse temperature

$705^{\circ} \mathrm{C}$ (a slightly higher collapse temperature compared to the NLFEA validation model, which collapsed at $682^{\circ} \mathrm{C}$ ). A model with fully fixed bases and in-plane restraint demonstrated a similar collapse temperature of $705^{\circ} \mathrm{C}$, with collapse being initiated by rafter buckling.

As the SCI guidance does not explicitly specify allowance for in-plane restraint from side rails, the study was extended to investigate models with no in-plane restraint. However, the SCI design guidance does imply that 'fixed' bases should be used for hot-rolled steel portal frames in fire boundary conditions.
Such an assumption may be unrealistic for cold-formed steel portal frames owing to the thin-walled nature of the columns and effects of bolt bearing resulting in semi-rigidity. Therefore, three different base configurations were investigated: fully pinned, fully fixed and partially fixed.

As can be seen in Figure 17, the three models with no in-plane restraint fail at a lower temperature than the model with inplane restraint. It was found that the fully fixed base condition failed at a temperature of $614^{\circ} \mathrm{C}$, and models with partially fixed and fully pinned bases both failed at $579^{\circ} \mathrm{C}$. This 
Structures and Buildings

Volume 169 Issue SB1
Finite-element investigation of cold-

formed steel portal frames in fire

Johnston, Lim, Lau et al.

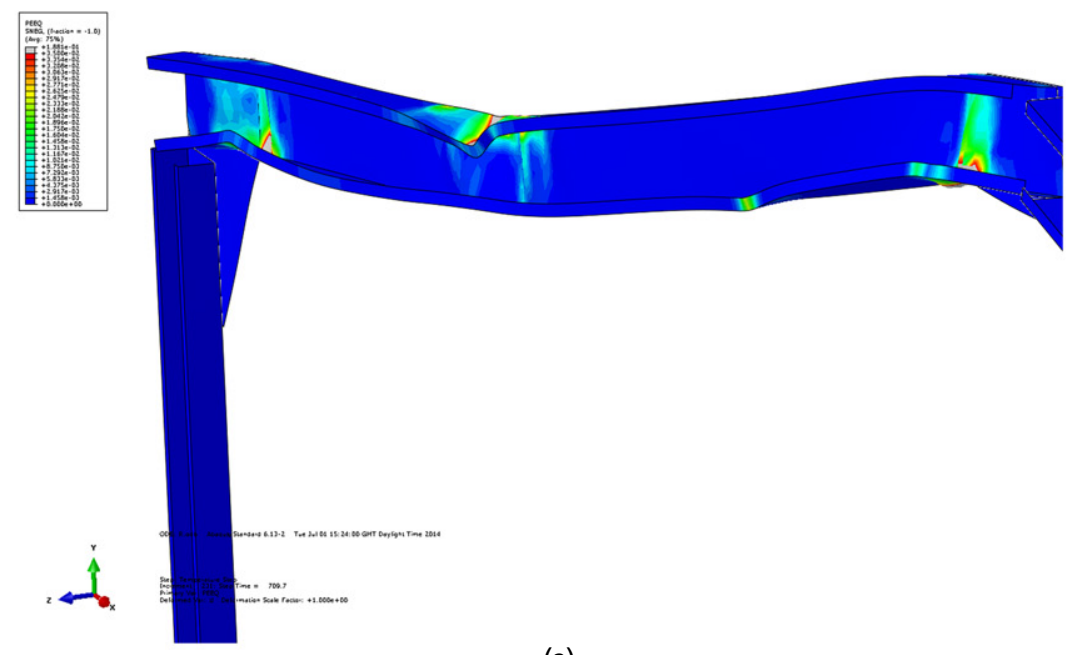

(a)

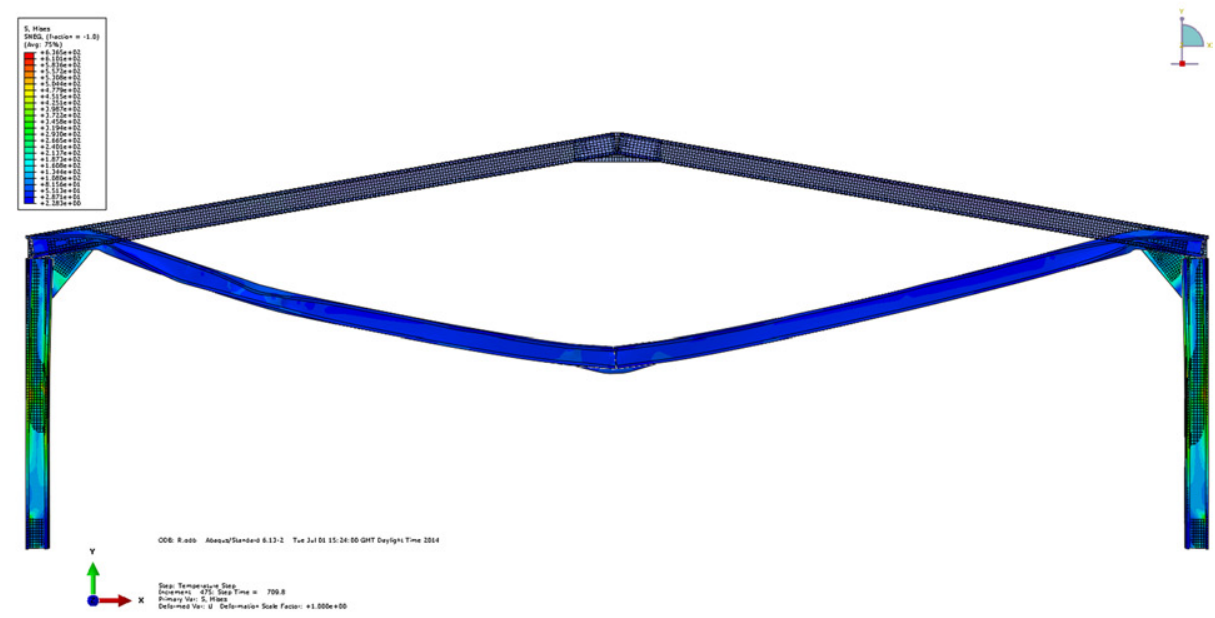

(b)

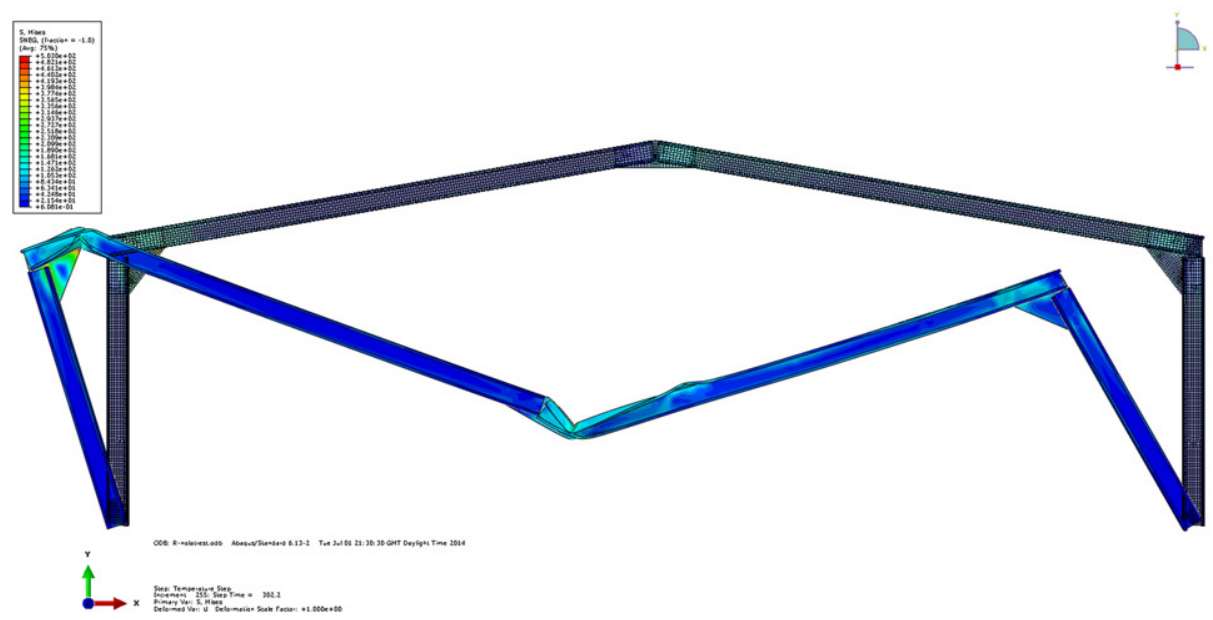

(c)

Figure 16. Investigation into effect of $\mathrm{SCl}$ design

recommendations: (a) initial yielding of section along rafter;

(b) deformed shape at $704^{\circ} \mathrm{C}$; (c) idealisation without in-plane restraint at $579^{\circ} \mathrm{C}$ 


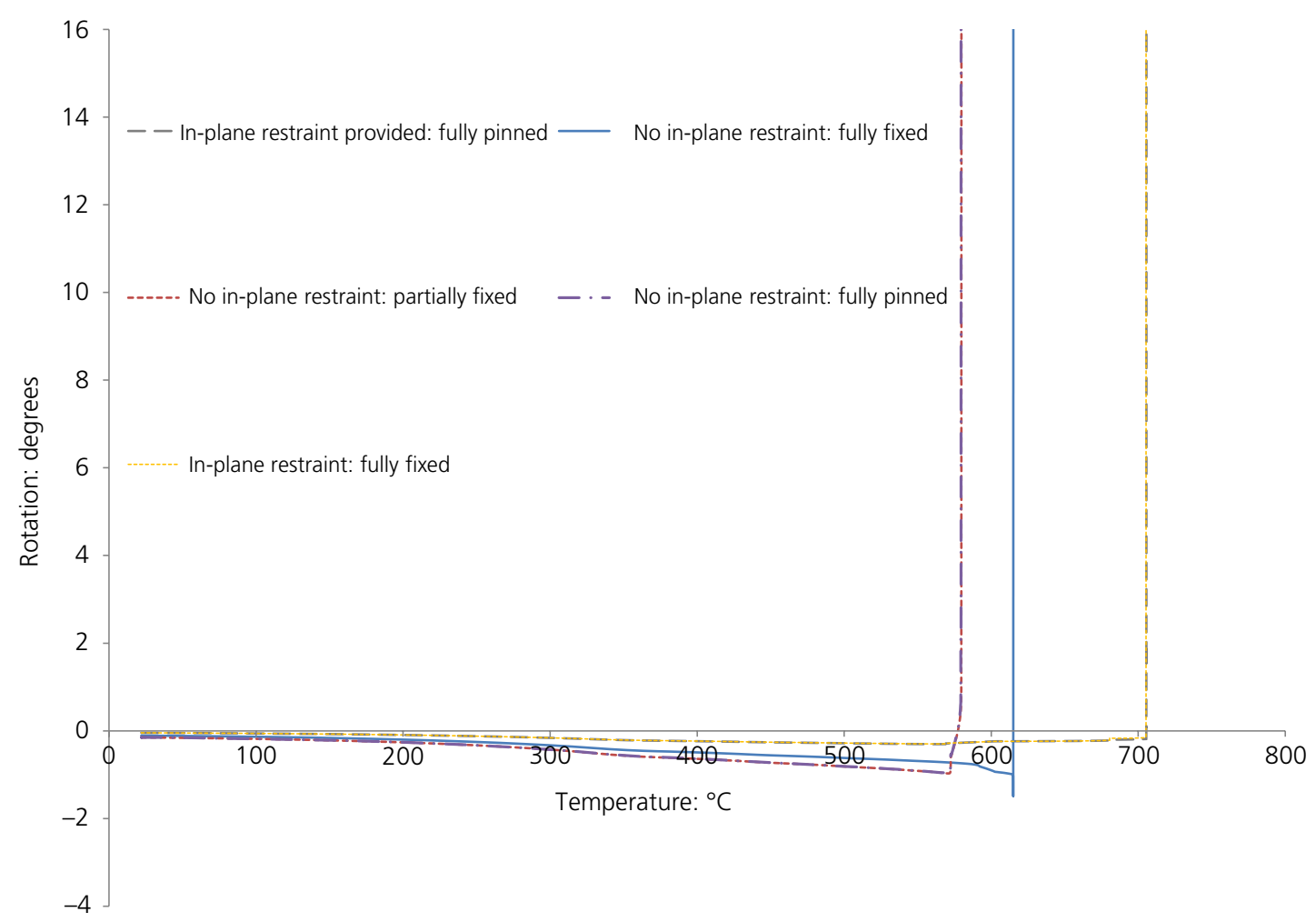

Figure 17. Investigation into effect of $\mathrm{SCl}$ design recommendations

demonstrates once again that the in-plane restraint from side rails plays a beneficial role in the performance of coldformed steel portal frames in fire, perhaps more importantly than for hot-rolled steel portal frames. It was observed that only a fully fixed base condition prevented the undesirable outwards sway failure. As this is not a realistic assumption in practice, it is therefore recommended that side rails should be protected to ensure in-plane restraint and outwards collapse.

\subsection{Full building arrangement model}

The effect of a full building arrangement model, which includes purlins and side rails, is presented. The thermocouple readings from the site test were input to the full building arrangement model. Loading was applied to the model as per the site test. Figure 18 shows the full building geometry model subjected to the early stages of fire effects. As can be seen, the five portals are laterally restrained with purlins and side rails, which are in turn tied back to each gable. Connector elements were again used to idealise each screw connection.

The collapse temperature for the full building arrangement model was $704^{\circ} \mathrm{C}$, which is closer to the experimental results of $714^{\circ} \mathrm{C}$ than the single portal model, which collapsed at $682^{\circ} \mathrm{C}$. The slight increase in failure temperature over the single portal model can be explained by the beneficial effect of secondary structural elements and stiffness from the gable end.

The model was then used to investigate the effect of only the central portal being exposed to fire, up to the temperature of $714^{\circ} \mathrm{C}$ that was recorded in the site test (Figure 19). As can be seen, the central portal rafter (the only rafter to be subjected to elevated temperatures) is held in catenary action by the purlins at $714^{\circ} \mathrm{C}$. The side rails act in tension, connected back to adjacent frames to prevent outwards movement of the column. This again shows that the secondary structural members help to prevent an undesirable collapse mechanism.

\section{Conclusion}

This paper has described the results of a full-scale fire test on a cold-formed steel portal frame building. The building was subject to a non-uniform natural fire. A non-linear elastoplastic FE shell model has also been described. The collapse temperature of the building from the fire test and that predicted using the $\mathrm{FE}$ shell model are $714^{\circ} \mathrm{C}$ and $682^{\circ} \mathrm{C}$, respectively. The result for a model using SCI design guide assumptions (but with pinned bases) demonstrates collapse at $705^{\circ} \mathrm{C}$. The result for the developed full building geometry model (which includes primary and secondary structural members) demonstrates collapse at $704^{\circ} \mathrm{C}$. From the results 


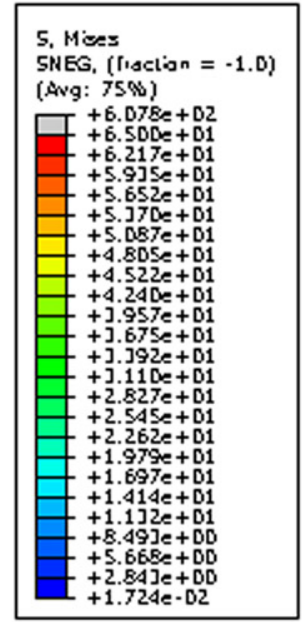

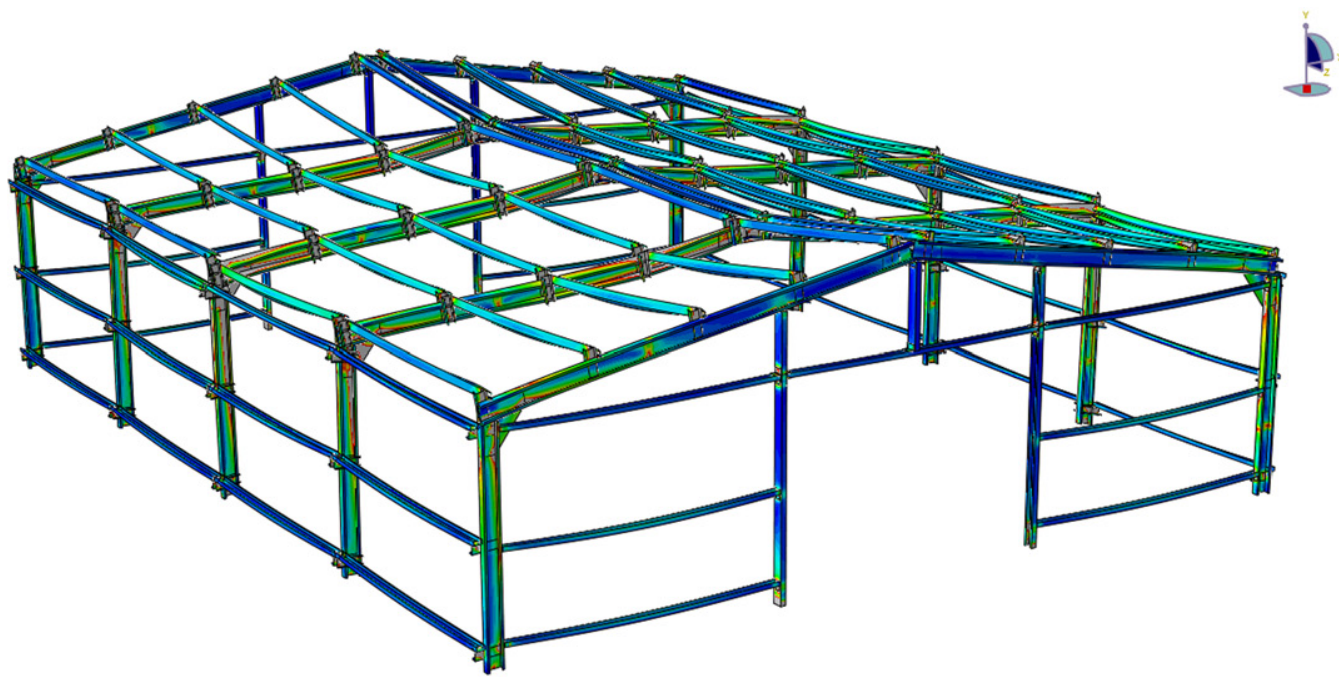

Figure 18. FE model of full building geometry prior to collapse at $704^{\circ} \mathrm{C}$

of the investigations carried out, the following conclusions are reached.

- Failure of the frame is not due to failure of the screws.

- The in-plane restraint provided by side rails and cladding ensures inwards collapse and prevents premature collapse. For cold-formed steel frames, side rails should therefore be protected along their entire length in order to ensure continued in-plane and out-of-plane restraint to the column.

Further research will investigate the effect of initial imperfections and quantify actual base fixity. Details of this investigation will be reported in the $\mathrm{PhD}$ thesis of the first author (Johnston, 2015).

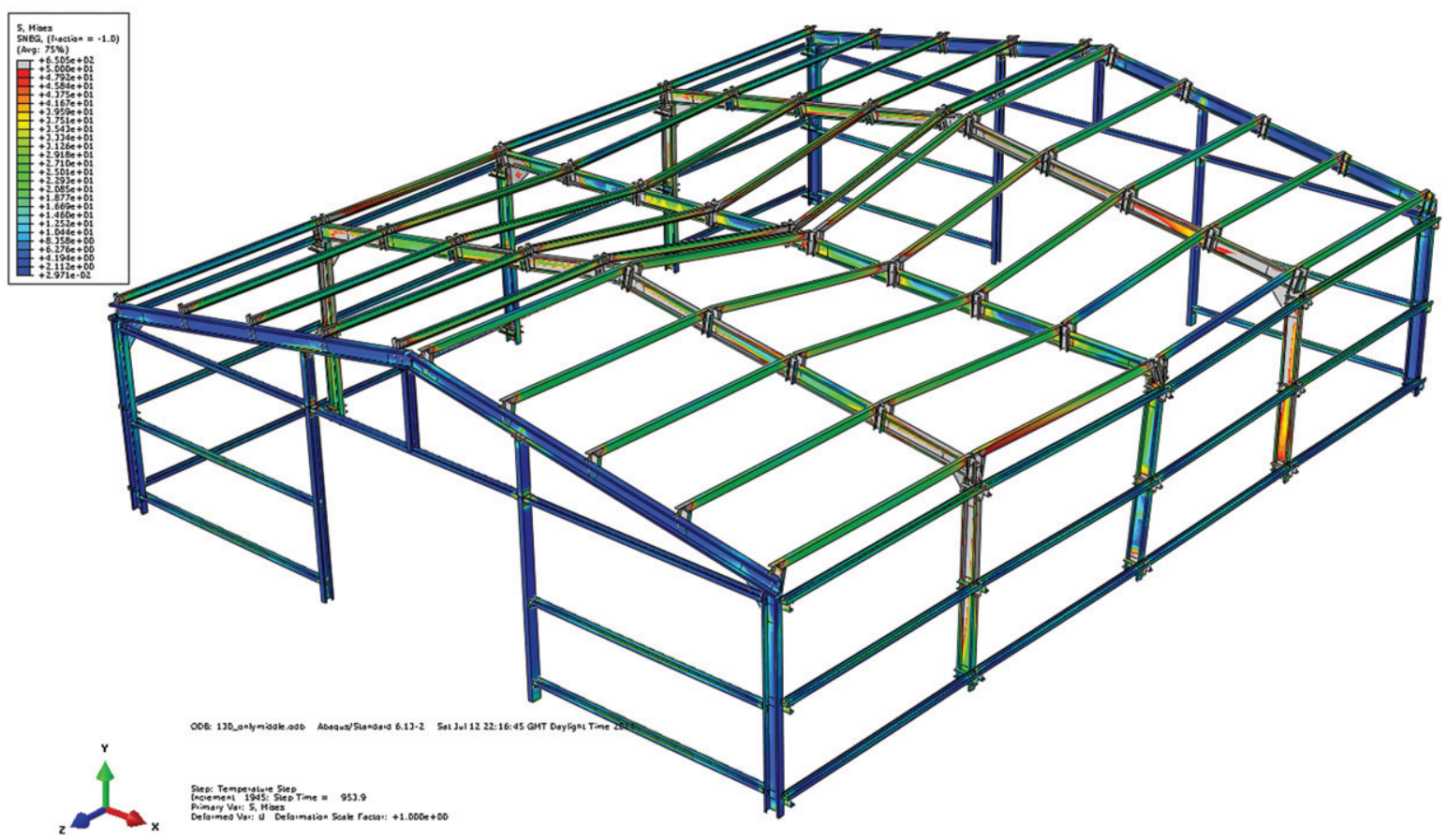

Figure 19. FE model of full building geometry with central portal held in catenary action at $714^{\circ} \mathrm{C}$ 
The practical relevance of this research will be to form the basis of a performance-based design method for single-storey cold-formed steel portal frames in fire boundary conditions. As the collapse temperature predicted using the FE shell model is conservative compared with that recorded for the fire test, in the absence of further test results, the shell model can be used to assist with the design of such frames in fire boundary conditions. The typical failure temperature and mechanism are demonstrated, as is the importance of secondary structural members in preventing undesirable outwards lateral collapse.

\section{Acknowledgements}

The authors would like to acknowledge gratefully the financial support from the ICE Research and Development Fund, IStructE Research Fund, and EcoSteel Sdn Bhd. The first author was funded through a DEL scholarship award, which is gratefully acknowledged. The authors would like to thank Dr Christine Switzer, Dr Jim Leinster, Mr David Scott, Mr Ross McKinstray, Mr Kok Mun Chooi and Mr Andrzej Wrzesien for their assistance.

\section{REFERENCES}

Bong MW (2005) Structural Fire Performance of Steel Portal Frame Buildings. MSc thesis, University of Canterbury, Canterbury, New Zealand.

BSI (2005) BS EN 1993-1-2: Eurocode 3: Design of steel structures. Part 1-2: General rules - Structural fire design. BSI, London, UK.

Chen J and Young B (2007) Experimental investigation of cold-formed steel material at elevated temperatures. Journal of Thin-Walled Structures 45(1): 96-110.

Chung KF and Lau L (1999) Experimental investigation on bolted moment connections among cold-formed steel members. Engineering Structures 21(10): 898-911.

Dassault Systèmes (2013) Abaqus Standard User's Manual, Version 6.13-1. Dassault Systémes, France.

Dubina D, Stratan A, Ciutina A, Fulop L and Zsolt N (2004) Monotonic and cyclic performance of joints of cold formed steel portal frames. Proceedings of the 4th International Conference on Thin-Walled Structures (Loughlan J (ed.)). IOP Publishing Ltd., Loughborough, UK, pp. 381-388.

HMG (Her Majesty's Government) (2006) Approved Document B: Fire Safety - Volume 2, Buildings Other Than

Dwellinghouses. The Building Regulations 2010

(for use in England). NBS, London, UK.

Johnston RPD (2015) Investigation of Cold-formed Steel Portal Frames at Ambient and Elevated Temperatures. $\mathrm{PhD}$ thesis, Queen's University Belfast, Belfast, UK.

Johnston RPD, Lim JBP, Sonebi M and Armstrong CG (2014) Cold-formed steel portal frames at elevated temperatures. In Benchmark Studies: Verification of Numerical Models in Fire Engineering, COST Action TU0904 Integrated Fire Engineering and Response (Wald F, Burgess I,
Kwasniewski L, Horová K and Caldová E (eds)). CTU Publishing House, Czech Technical University in Prague, Prague, Czech Republic, vol. 1, pp. 230-244.

Johnston RPD, Lim JBP, Xu Y et al. (2015) Cold-formed steel portal frames in fire: Full-scale test and finite element analysis. The Structural Engineer 92(10): 44-50.

Kallerova P, Wald F and Sokol Z (2009) Connections of trapezoidal sheets under fire. Acta Polytechnia, Czech Technical University Publishing House 49(1): 82-86.

Lee J, Mahendran M and Makelainen P (2003) Prediction of mechanical properties of light gauge steels at elevated temperatures. Journal of Constructional Steel Research 59(12): $1517-1532$.

Lim JBP and Nethercot DA (2004) Finite element idealization of a cold-formed steel portal frame. Journal of Structural Engineering 130: 78-94.

Mecozzi E and Zhao B (2005) Development of stress-strain relationships of cold-formed light weight steel at elevated temperatures. Proceedings of Eurosteel Conference, pp. 5.1-41-5.1-49.

Mills J and LaBoube R (2004) Self-drilling screw joints for cold-formed channel portal frames. Journal of Structural Engineering, ASCE 130(11): 1799-1806.

O'Meagher AJ, Bennetts ID, Dayasawa PH and Thomas IR (1992) Design of single storey industrial buildings for fire resistances. Journal of the Australian Institute of Steel Construction 26(2): 1-17.

Outlinen J (1999) Mechanical Properties of Structural Steels at Elevated Temperatures. Licentiate thesis, Helsinki University of Technology, Helsinki, Finland.

Pham CH and Hancock GJ (2010) Numerical Simulation of High Strength Cold-formed Supacee Sections in Combined Bending and Shear. School of Civil Engineering, The University of Sydney, New South Wales, Australia, Research Report R913.

Pyl L, Schueremans L, Dierckx W and Georgieva I (2012) Fire safety analysis of a 3-D frame structure consisting of cold-formed sections; numerical modelling versus experimental behaviour based on a full-scale fire test. Journal of Thin-Walled Structures 61: 204-212.

Rahman M, Lim JBP, Xu Y et al. (2013) Effect of column base strength on steel portal frames in fire. Proceedings of the Institution of Civil Engineers - Structures and Buildings 166(4): 197-216, http://dx.doi.org/10.1680/stbu. 11.00040.

Ranawaka T and Mahendran M (2009) Experimental study of the mechanical properties of light gauge cold-formed steels at elevated temperatures. Fire Safety Journal 44(2): 219-229.

Rhodes J and Burns R (2006) Development of a portal frame system on the basis of component testing. Proceedings of the 18th International Speciality Conference on Cold-Formed Steel Structures, Missouri, USA (Roger A. LaBoube and Wei-Wen Yu (eds)). Missouri University of 
Science and Technology, St Louis, Missouri, USA, pp. 367-385.

Sabbagh AB, Petkovski M, Pilakoutas K and Mirghaderi R (2013) Cyclic behaviour of bolted cold-formed steel moment connections: FE modelling including slip. Journal of Construction Steel Research 80: 100-108.

Simms W and Newman G (2002) Single-Story Steel Framed Buildings in Fire Boundary Conditions. The Steel Construction Institute, Berkshire, UK, SCI Publication P313.

Song Y, Huang Z, Burgess I and Plank R (2009) The behaviour of single-storey industrial steel frames in fire.
International Journal of Advanced Steel Construction 5(3): 289-302.

Wong Y (2001) The Structural Response of Industrial Portal Frame Structures in Fire. PhD thesis, University of Sheffield, Sheffield, UK.

Wrzesien A, Lim JBP and Nethercot DA (2012) Optimum joint detail for a general cold-formed steel portal frame. Advances in Structural Engineering 15(9): 1623-1639.

Yan S and Young B (2012) Screwed connections of thin sheet steels at elevated temperatures - part 1: steady state tests. Engineering Structures 35: 234-243.

\section{WHAT DO YOU THINK?}

To discuss this paper, please email up to 500 words to the editor at journals@ice.org.uk. Your contribution will be forwarded to the author(s) for a reply and, if considered appropriate by the editorial panel, will be published as discussion in a future issue of the journal.

Proceedings journals rely entirely on contributions sent in by civil engineering professionals, academics and students. Papers should be 2000-5000 words long (briefing papers should be 1000-2000 words long), with adequate illustrations and references. You can submit your paper online via www.icevirtuallibrary.com/content/journals, where you will also find detailed author guidelines. 